\title{
LAS GARANTIAS INDEPENDIENTES EN EL DERECHO ESPAÑOL Y SU ACEPTACION POR LA JURISPRUDENCIA
}

\author{
Javier San Juan Crucelaegui \\ Doctor en Derecho \\ Profesor de la Universidad de Deusto
}

Sumario: I. Las dificultades iniciales para la aceptación de la figura. II. La tipología de las garantias independientes: 1. La utilización inicial de las garantías independientes; 2. Las modalidades de garantías independientes: A) La garantía independiente simple a primera demanda; B) La garantía documentaria; C) La garantía justificada a primera demanda.III. La garantía independiente y figuras afines. IV. La naturaleza jurídica de la garantía independiente: 1. Las relaciones involucradas y la preeminencia de la relación de garantía; 2. Los caracteres de las garantías independientes: A) La independencia de la garantía: a) La independencia de la garantía y su desconexión del resto de relaciones; b) La paralela independencia de la contragarantía; c) Independencia e inoponibilidad de excepciones derivadas del contrato subyacente. B) El carácter unilateral de la garantía: a) La voluntad unilateral como fuente de obligaciones en el sistema español; b) El carácter unilateral de la garantía independiente en el Derecho español. C) La inapropiada consideración de la garantía independiente como garantía de resultado: el carácter indemnizatorio de la garantía independiente. 3. La calificación jurídica de la figura de las garantías independientes: A) Las garantías independientes como contrato «sui generis»; B) Las garantías independientes en la jurisprudencia de los Tribunales españoles y su configuración como promesa unilateral de pago. V. El régimen jurídico de las garantías independientes: las condiciones para su validez: 1 . La forma de la garantía; 2 . La capacidad de las partes; 3 . El consentimiento; 4. La causa de la garantía independiente: A) La causa del contrato; B) La distinción entre negocios iniciales y negocios ejecutivos; C) La causa de la garantía independiente; D) La abstracción funcional de la garantía independiente y sus efectos. 5 . El objeto de la garantía independiente.

La aparición de la figura de las garantías independientes, el reconocimiento de su configuración esencial y la utilización general que reciben se ha producido en el ámbito del comercio internacional del que son originarias, de forma que dichas garantías revisten primordialmente tal carácter de internacionalidad, aunque su utilización no queda constreñida a 
las operaciones de comercio exterior puesto que se encuentran igualmente en las operaciones de comercio interno. CABRILlac y Mouly ${ }^{1}$ la definen como el compromiso de pagar una suma determinada asumido en garantía de la ejecución de una operación económica de la que es independiente, de manera que su beneficiario no podrá oponer las excepciones que pudieran derivarse de la relación subyacente garantizada. En cuanto figura de nuevo cuño, decantación y cristalización de las prácticas jurídicas propias de las relaciones comerciales internacionales, carente por tanto de regulación legal específica y desarrollada al amparo de la jurisprudencia, ha suscitado controversia y opiniones encontradas ${ }^{2}$.

Unos se han decantado en su favor por estimar que de ellas se deriva una composición más apropiada o armoniosa del equilibrio de las prestaciones contractuales que se traduce en un grado mayor de seguridad en las relaciones internacionales. Se apoya esta consideración, desde un punto de vista jurídico, en la comparación de la situación y efectos de las garantías independientes con los producidos por la constitución de un depósito de dinero o valores negociables en poder del acreedor, situación ésta contemplada y admitida por la generalidad de los ordenamientos jurídicos, que no suscita oposición alguna en cuanto

1 Cfr. Cabrillac y Mouly, Droit des Suretés, París, Litec, 4. ${ }^{\text {a }}$ ed., 1997, pág. 329; la definición de SimLER, Le cautionnement et les garanties autonomes, París, Litec, 2. ${ }^{\text {a }}$ ed., 1992, pág. 675, es muy similar: «un engagement de payer une certaine somme, pris en considération d'un contrat de base et á titre de garantie de son exécution, mais constituif d'une obligation indépendante du contrat garanti et caracterisé par l'inopposabilité des exceptions tirées de ce contrat»; asimismo, la definición de MATTout, Droit bancaire international, París, Banque, 1996, p. 155, para quien «la garantie á premiére demande est un engagement par lequel le garant, á la requête irrévocable d'un donneur d'ordre, accepte de payer en qualité de debiteur principal sur simple demande, une somme d'argent á un bénéficiaire désigné, dans les termes et conditions stipulés dans la garantie, en renonçant par avance á exercer tout contrôle externe sur les conditions de mise en jeu de son engagement».

${ }^{2}$ En cuanto a la doctrina española acerca de las garantías independientes, vid. CARrasco Perera, Fianza, accesoriedad y contrato de garantía, La Ley, 1992, pp. 9-36; CARrillo Pozo, Las garantías autónomas en el comercio internacional, Studia Albornotiana, Bolonia, 2000; CERDÁ Olmedo, Garantía independiente, Granada, Comares, 1991; CREMAdes, Afianzamiento y garantías en el comercio internacional, en «Conferencias sobre Derecho bancario internacional», La Ley, 1985; DíAz MoRENo, Las garantías a primer requerimiento (garantías a primera demanda), en «Las garantías a primer requerimiento», Sánchez Calero dir. Civitas-Fundación BBV, Madrid, 1996, págs. 117-150; ECHENIQUE GoRDILlO, «Las garantías bancarias internacionales: algunas consideraciones», en Revista de Derecho Bancario y Bursátil, 1982, pp. 147-163; MARTíneZ CALCERRADA, «El contrato de fianza y otras garantías personales en su tratamiento legal y Jurisprudencia del Tribunal Supremo», en La Ley, 3043, (10 de julio de 1992), pp. 817-832; SÁnChEZ CALERo, «Garantías a primer requerimiento», en «Las garantías a primer requerimiento», cit. pp. 29-63; SÁNCHEZ-CALERo GuILARTE, El contrato autónomo de garantía. Las garantías a primera demanda, Centro de documentación bancaria y bursátil, 1995. 
a su valoración y aceptación jurídicas, de la cual las garantías independientes vendrían a ser una alternativa que puede ser considerada como más favorable para el deudor garantizado.

En el polo de atracción opuesto se encuentran aquellas otras corrientes de opinión, decididamente enfrentadas a la figura de las garantías independientes, que fundamentan su rechazo a las mismas en el inaceptable apremio de la situación del ordenante, que se manifiesta en el hecho de que el beneficiario está formalmente legitimado para la reclamación de la ejecución de la garantía aun en el caso de que no se hubieren dado los supuestos previstos en la relación subyacente garantizada, situación ésta que, considerada desde un punto de vista jurídico, se sostiene podría suponer un desequilibrio de la igualdad contractual y una quiebra de la seguridad jurídica de las partes contratantes, así como la ruptura del principio de que el cumplimiento de los contratos no puede dejarse al arbitrio de uno solo de los contratantes y se ha afirmado que las garantías independientes son inopportunes en pratique et malsaines en principe ${ }^{3}$.

Otra corriente de pensamiento no se opone a la aceptación general y básica de las garantías independientes sino a su admisibilidad en cuanto figura jurídica específica y diferenciada, fundamentando ${ }^{4}$ tal oposición en la necesidad y obligación de reconducción de la figura al tipo de la fianza de la que vendría a constituir una especial variación ${ }^{5}$ caracterizada por la exclusión de los rasgos y caracteres más significativos de aquella, tales como su accesoriedad o la posibilidad del fiador de oponer las excepciones derivadas de la obligación afianzada, todo ello con fundamento en el principio de libertad contractual de las partes.

\section{Las dificultades iniciales para la aceptación de la figura}

La mayor parte de los sistemas jurídicos mostraron titubeos iniciales para la aceptación de la garantía independiente como figura jurídica

3 Cfr. Guide pour les garanties bancaires, les soumissions cautionnées et les garanties de bonne fin, «Section des entrepreneurs internationaux», Comité de la Cámara de Comercio Internacional; en parecido sentido, DuBISSON, Le droit de saisir les cautions de soumission et les garanties de bonne exécution, en «Droit et Pratique du Commerce International», 1977, p. 423; CREMADES, art. cit. pp. 76-77.

${ }^{4}$ Cfr. CARrasco Perera, op. cit., pp. 9-36. El autor se pronuncia en contra de la admisión de la figura en cuanto tal, reconduciéndola al tipo contractual de la fianza.

5 Las divergencias acerca de las garantías personales fueron el objeto de los trabajos de armonización de los ordenamientos jurídicos europeos llevados a cabo por el MAX PLANCK INSTITUT (Hamburgo), Le cautionnement dans le droit des pays membres de la communauté européenne, en «Travaux de la Commission des Communautés Européennes», Série Concurrence, n. ${ }^{\circ}$ 14, Bruselas, 1971. 
específica y diferenciada. Tales dudas se manifestaron bien haciendo depender tal aceptación de la identificación de su causa negocial, bien tendiendo a su reconducción a los moldes tradicionales de la fianza, tendencia ésta particularmente presente en los primeros pronunciamientos jurisprudenciales, o bien, confundiendo su carácter no accesorio con la consideración acerca de su naturaleza causal o abstracta. Las objeciones con las que inicialmente se encontraron los sistemas jurídicos para la aceptación de la garantía independiente, lo fueron en relación con su incardinación en la categoría de las garantías personales pues, si la garantía independiente es una clase de garantía personal, por ello mismo le será consubstancial su carácter accesorio al constituir garantía de una obligación principal, de forma que, en defecto de ésta, perdería todo significado. Por tanto, la accesoriedad es rasgo común a todas las formas de garantía personal por lo que las partes no pueden proceder a su derogación. Otras veces, se consideró que el reconocimiento de la naturaleza abstracta de una garantía personal se opone a su validez porque todo acto jurídico debe tener una causa. En otras ocasiones, el problema para el reconocimiento de las garantías independientes estribó en la carencia de diferenciación entre el carácter principal y la causalidad de la garantía ${ }^{6}$.

Pronunciamientos hostiles se han dado asimismo en nuestra jurisprudencia, inspirados en una actitud de rechazo conceptual de la figura. Los hechos de la STS de 2 de octubre de $1990^{7}$, se referían a una «fianza definitiva» prestada por el Banco Pastor a favor de una constructora para responder de la ejecución de unas obras encargadas por una comunidad de propietarios a dicha constructora, añadiéndose que la fianza se constituía bajo la modalidad conocida como «aval a primera demanda» o «a primer requerimiento». La citada STS, tras recordar que «el contrato de fianza es definido por el Código civil como aquél por virtud del cual se obliga uno a pagar o cumplir por un tercero, en el caso de no hacerlo éste», pasa a la formulación de algunas precisiones entre las que señala que «el fiador puede obligarse a menos, pero no a más que el deudor principal, tanto en la cantidad como

6 Como exponente de tales titubeos, puede verse la sentencia la Cour d'Appel de París, de 15 de junio de 1973, «Banque du Caire c. S.P.B», en Rev. Jurisprudence Commerciale, 1973 , p. 273, en la cual no se aceptó la validez de una garantía independiente como tal, sino que el aseguramiento fue calificado de fianza por el tribunal bajo el argumento de que «toute sureté personnelle a un caractére accesoire». Al argumentar tal rechazo, el juez se refirió al principio de inadmisibilidad de los actos abstractos en derecho francés. El razonamiento confunde la no accesoriedad y la naturaleza abstracta de la garantía personal en cuestión.

7 STS de 2 de octubre de 1990, en Rep. Aranzadi, 1990, n. ${ }^{\circ} 7.464$. 
en lo oneroso de las condiciones. Si se hubiera obligado a más, se reduciría su obligación a los límites de la del deudor». A continuación, se pronuncia en contrario frente al reconocimiento de las garantías independientes:

«...la pretendida interpretación que el recurrente hace en el desarrollo del motivo...desnaturaliza el contrato de fianza, convirtiéndolo en un simple reconocimiento de deuda, al pretender que el avalista venga obligado a pagar siempre y en todo caso, cualquiera que fuesen las obligaciones afianzadas; supuesto que no puede ser el de autos, por mucha amplitud o sentido interesado que quiera dársele a las expresiones «aval a primera demanda»o «primer requerimiento», pues los términos demanda y requerimiento hay que ponerlos necesariamente en relación con la frase anterior «obligaciones derivadas del contrato» y sólo cuando estas obligaciones válidamente existan, vendrá obligado el fiador....».

Junto a la citada sentencia, la STS de 15 de abril de $1991^{8}$, se refería a una garantía otorgada por el entonces Banco de Bilbao a favor de una constructora y frente a una sociedad promotora de viviendas, para responder frente a ésta última de la existencia de vicios o defectos que pudieran afectar a unos apartamentos, expresándose que la garantía tenía carácter solidario, con renuncia expresa a los beneficios de excusión o división, y que el banco abonaría cualquier importe hasta el límite garantizado, al primer requerimiento. Esgrimiendo defectos en lo construido, la promotora demandó al banco y a la empresa constructora, demanda que acabó por ser desestimada al no resultar procedente la condena contra ésta última. Al respecto, afirma la STS citada:

«...si conforme previene el párrafo primero del art. 1822 del Código Civil, por la fianza «se obliga uno a pagar o cumplir por un tercero en el caso de no hacerlo éste», necesariamente se requiere para efectividad, que venga reconocido el incumplimiento gene rante de responsabilidad, que el aval garantizaba, en ortodoxa aplicación del principio de derecho de que no producido el antecedente, no puede darse el consiguiente, ya que faltando la causa no puede darse el efecto».

Parece latir en ambas sentencias la idea de la imposibilidad en nuestro sistema jurídico de otras formas de garantía diferenciadas de la fianza, puesto que los caracteres de ésta última, la subsidiariedad, la accesoriedad y la consiguiente consecuencia de imposibilidad de la fianza in duriorem causam, parecen ostentar rango esencial, de manera que no cabría una forma de aseguramiento que no los ostentara o, por

8 STS de 15 de abril de 1991, en Rep. Aranzadi, 1991, n. ${ }^{\circ} 2.693$. 
el contrario, si así lo hiciera, quedaría automáticamente reconducida a los moldes de la fianza ${ }^{9}$.

La categoría de las garantías personales ha sido tradicionalmente considerada como compuesta por un reducido catálogo de tipos contractuales entre los que cabría incluso la sola enunciación de dos, que resultarían ser la fianza y el aval, siendo aquella el tipo paradigmático. Frente al mencionado punto de vista tradicional, la generalidad de los ordenamientos jurídicos considera que el principio de libertad contractual de las partes permite a éstas la creación de garantías personales desprovistas de los caracteres tradicionalmente a aquellas atribuidos, siendo la garantía independiente una de dichas creaciones. A diferencia de las doctrinas alemana ${ }^{10}$ e italiana ${ }^{11}$, las cuales han analizado el ensanchamiento del tipo contractual de la fianza para introducir en él la figura de las garantías independientes, la doctrina francesa ${ }^{12}$ ha partido

9 Comentarios a la jurisprudencia del TS en Blanco CAmPaña, Aval cambiario y aval como contrato de garantía, en «Comentarios a jurisprudencia de derecho bancario y cambiario», en CDBB, Madrid, 1993, vol. I, pp. 167-182; CoCA y FLAQUER, Nota sobre el aval a primer requerimiento en la Jurisprudencia del Tribunal Supremo, en Estudios de derecho bancario y bursátil, Homenaje a Evelio Verdera», tomo I, p. 627; DíAz Moreno, Las garantías a primer requerimiento en la jurisprudencia del Tribunal Supremo, en «Estudios de derecho bancario y bursátil, Homenaje a Evelio Verdera», La Ley, 1994, págs. 627-650; MARIMÓN DURA, «Ultima jurisprudencia sobre el contrato de garantía a primer requerimiento», en Revista General de Derecho, 1993, pp. 3.057-3.075; SÁNCHEZ-CALERo GuILARTE, «El reconocimiento jurisprudencial de la garantía, a primera solicitud, en Revista Derecho Bancario y Bursátil, 1993, pp. 541-561; aun acerca del crédito documentario, la analogía entre éste y las garantías independientes confieren gran interés al trabajo de Alonso UReBA, En torno al crédito documentario con particular referencia a las modalidades de créditos transferibles y subsidiarios, en «Nuevas entidades, figuras contractuales y garantías en el mercado financiero», Madrid, 1990, pp. 454-485.

10 El origen y utilización internacionales de las garantías independientes impone su construcción con una óptica transnacional, lo que lleva a tomar en consideración los desarrollos producidos en otros ámbitos jurídicos. En cuanto a la doctrina de inspiración germánica, y por lo que a la doctrina alemana se refiere, vid. CAEMMERER, Bankgarantien im Aussenhandel, en «Festschrift fur O. Riese», Karlsruhe, 1964, pp. 295-307; CANARIs, Bankvertragsrecht, Erster Teil, Berlín, 3. ${ }^{a}$ edición, 1988, pp. 571 y sigs; PLEYER, République Fédérale d'Allemagne, en «Les garanties bancaires dans les contrats internationaux», cit. pp. 185-196. Respecto de la doctrina suiza, DoHm, Les garanties bancaires dans le commerce international, Berna, Staemphli \& Cie, 1986.

11 La doctrina italiana ha sostenido la posibilidad de configurar formas atípicas de fianza: cfr. Fragali, Fideiussione, en «Enciclopedia del Diritto», Milán, Giuffré, tomo XVII, pp. 95-109. Ello ha concitado la oposición de quienes defienden el contrato de garanzia pura. Benatti, Il contrato autonomo di garanzia, en «Banca, Borsa e Títoli di crédito», 1982, pp. 1.971 y ss.; MAZZONI, Les garanties bancaires en droit italien, en «les garanties bancaires dans les contrats internationaux, cit., pág. 292.

12 En la doctrina francesa CABrillac y Mouly, op. cit., pp. 329-386; Gavalda y STOUfFlet, «La lettre de garantie internationale», en Rev. Trimestrielle de Droit Commer- 
de un punto de vista diferente consistente en la apreciación del agotamiento de la fianza para la cobertura de los riesgos inherentes a las actuales relaciones mercantiles internacionales, por lo que ha procurado establecer el fundamento de otras nuevas garantías personales no accesorias diferenciadas del tipo de la fianza. El carácter no accesorio de la garantía independiente no equivale a la negación de su pertenencia a la categoría de las garantías personales, pues la garantía, aun no accesoria, continúa siendo subsidiaria pues se refiere a una operación económica cuyo buen fin asegura.

Tras las iniciales vacilaciones ante la aparición de un mecanismo jurídico novedoso, las garantías independientes han sido finalmente aceptadas por los ordenamientos jurídicos ${ }^{13}$ a pesar de las diferentes orientaciones y pautas que los inspiran. Cabe afirmar que, en la actualidad, esta general aceptación reviste además un substancial grado de uniformidad entre los diversos sistemas jurídicos ${ }^{14}$. Aún así, la configuración y caracterización de la figura y el establecimiento de su régimen jurídico suscitan un especial interés, puesto que las garantías independientes, en cuanto consecuencia o derivación de las prácticas jurídicas habitualmente observadas en el ámbito del comercio internacional, carecen de normativa legal específica que les fuere de aplicación, por lo que su construcción jurídica se ha desarrollado al amparo de los pro-

cial, 1980, pp. 1-23; MAtTout, Droit bancaire international, cit. pp. 146-195; RIVES Lange y Contamine Raynaud, Droit Bancaire, París, Précis Dalloz, 1995; Simler, op. cit., pp. 675-757; VASSEUR, «Dix ans de jurisprudence francaise relative aux garanties independantes», en Rev. de Droit des Affaires Internationales, 1990, pp. 239-294; VILLEREY, Les garanties bancaires en droit francais, en «Les garanties bancaires dans les contrats internationaux», cit. pp. 259-278.

13 En la doctrina británica, CHATTERJEe, «The independence of contracts of guarantee and counter-guarantee from the underlying contract», en Journal of International Business Law, 1995, pp. 130-135; GUTTERIDGE y MEGRAH, The law of bankers' commercial credits,

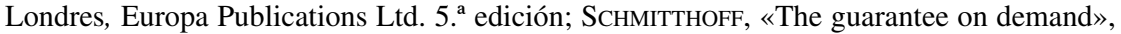
en Journal of Business Law, 1978, págs. 58-60.

14 Trabajos de inspiración transnacional son los de BERTRAMs, Bank Guarantees in International Trade, Kluwer Law International and The International Chamber of Commerce, 2. ${ }^{a}$ edición, 1996; HoRn y WyMEERSCH, Bank guarantees, Stand-by letters of credit and performance bonds in International trade, en «The Law of International Trade» Finance, Deventer, 1989, pp. 455-529; KozOLCHYK, «Bank guarantees and letters of credit: time for a return to the fold», en The Journal of International Business Lawyer, 1989, vol. 11, 1, pp. 3-79; PORTAle, Nuovi sviluppi del contrato autonomo di garanzia, en «Banca, Borsa e Títoli di Crédito», 1985, pp. 169-187; Poullet, Les garanties contractuelles dans le commerce international, en «Droit et Pratique du Commerce International», 1979, n. ${ }^{\circ} 3$, pp. 387-442; VASSEUR, Rapport de synthése:le droit des garanties dans les contrats internationaux en France et dans les pays de l'Europe de l'Ouest, en «Les garanties bancaires dans les contrats internationaux», cit. pp. 319-364. 
nunciamientos judiciales junto a los que deberán ser tomados en consideración los principios generales de derecho.

\section{La tipología de las garantías independientes}

La clasificación de las garantías independientes ha sido hecha con frecuencia por relación a los tipos de riesgos y obligaciones garantizadas. En los momentos iniciales tras la aparición de las garantías independientes, éstas recibieron una utilización exclusivamente circunscrita a determinados supuestos, lo que ha sido superado en la actualidad, por lo que tal clasificación tiene una importancia secundaria. En la actualidad, el riesgo que para el ordenante de la garantía significa el poder cuasi discrecional del beneficiario en orden a su ejecución ha llevado a las regulaciones uniformes internacionales a la preferencia por aquellos tipos de garantía cuya ejecución necesita la aportación de documentos adicionales convenidos por las partes. Surgen así clases diversas de garantías que, en general, son las denominadas garantías simples que se contraponen a las documentarias. La mención indistinta de las modalidades tradicionales y actuales de garantía y la variable terminología utilizada para su denominación significan un inicial factor de confusión ${ }^{15}$.

De entre las denominaciones utilizadas, dos subrayan el carácter específico de la figura: son las de garantía autónoma y la de garantía independiente. Esta última parece preferible por cuanto expresa la diferencia de naturaleza con la fianza por esencia accesoria ${ }^{16}$. Resulta ser, por otra parte, la expresión elegida por la Uncitral en su Convención reguladora y unificadora de las cartas de crédito stand-by y de las garantías independientes tal cual son practicadas en Europa.

15 La primera de ellas consiste en la expresión garantía contractual que parece haber sido abandonada. Las garantías son siempre contractuales por lo que tal denominación se resiente de ambigüedad. La denominación de garantía abstracta se presta a menor confusión pero no se corresponde con la realidad, puesto que las obligaciones son causales. Igualmente se ha sugerido la denominación de garantía automática, utilizada con la pretensión de conseguir un mayor resalte del rigor de la obligación del garante. Sin embargo, la noción de automaticidad no contiene un significado jurídico preciso. Otros autores se contentan con la expresión garantía bancaria, considerando que tales garantías son usualmente emitidas por instituciones bancarias. Ello es excesivamente genérico pues también la fianza o el aval son otorgados por bancos, al igual que las cartas de intención o de patronazgo. Igual crítica puede hacerse a la denominación de garantía internacional, puesto que las garantías analizadas no son necesariamente tales, mientras que otras garantías, particularmente una fianza, pueden igualmente ser internacionales.

16 Esta es la denominación adoptada por la Convención de las Naciones Unidas, Nueva York, 11 de diciembre de 1995, titulada «United Nations Convention on Independent Guarantees and Standby Letters of Credit». UN. Doc. A/CN.9/372. 


\section{La utilización inicial de las garantías independientes}

Las garantías independientes son susceptibles de múltiples usos, pudiendo ser utilizadas en toda clase de relaciones contractuales, tanto en transacciones internas como internacionales. Sin embargo, algunas modalidades indican, por la repetición de su utilización, que el campo predilecto de tales garantías está constituido por los contratos de ejecución de obra o de suministro. Se trata de tipos de garantías utilizadas en correspondencia con tres fases de las relaciones entre las partes: $\left.1 .^{a}\right) \mathrm{La}$ garantía de sumisión o de respeto a los términos y condiciones de una licitación, Tender guarantee o Bid Bond ${ }^{17} .2^{\text {a }}$ ) La garantía de devolución de pagos a cuenta o anticipos, Repayment guarantee, destinada a asegurar los adelantos monetarios hechos por el comprador o propietario de una obra ${ }^{18} .3 .^{a}$ ) La garantía de buen fin o de ejecución adecuada, Performance guarantee, que cubre la buena o adecuada ejecución del contrato, y que suele ascender a un porcentaje del importe total del contrato $^{19}$. Las mencionadas modalidades de garantía independiente parecen haber sido las que se desarrollaron inicialmente de forma mayoritaria en relación con contratos de ejecución de obra y de ingeniería ci-

17 Cfr. la definición de la Cámara de Comercio Internacional, Publicación n. ${ }^{\circ} 325$, Uniform Rules for Contract Guarantees, 1978, art. 2a, «For the purposes of these Rules: «tender guarantee» means an undertaking given by a bank, insurance company or other party («the guarantor») at the request of a tenderer («the principal») or given on the instructions of a bank, insurance company, or other party so requested by the principal («the instructing party») to a party inviting tenders («the beneficiary») whereby the guarantor undertakes-in the event of default by the principal in the obligations resulting from the submission of the tender-to take payment to the beneficiary within the limits of a stated sum of money; ...».

18 URCG, artículo 2c, «repayment guarantee» means an undertaking given by a bank, insurance company or other party («the guarantor») at the request of a supplier of goods or services or other contractor («the principal») or given on the instructions of a bank, insurance company or other party so requested by the principal («the instructing party») to a buyer or to an employer («the beneficiary») whereby the guarantor undertakes-in the event of default by the principal to repay in accordance with the terms and conditions of a contract between the principal and the beneficiary («the contract») any sum or sums advanced or paid by the beneficiary to the principal and not otherwise repaid-to make payment to the beneficiary within the limits of a stated sum of money».

19 URCG, artículo 2b: «performance guarantee» means an undertaking given by a bank, insurance company or other party («the guarantor») at the request of a supplier of goods or services or other contractor («the principal») or given on the instructions of a bank, insurance company or other party so requested by the principal («the instructing party») to a buyer or to an employer («the beneficiary») whereby the guarantor undertakesin the event of default by the principal in due performance of the terms of a contract between the principal and the beneficiary («the contract») to make payment to he beneficiary within the limits of a stated sum of money or, if the guarantee so provides, at the guarantor's option, to arrange for performance of he contract». 
vil en los países de Oriente Medio y, a su vez, provocaron el desarrollo de la noción de garantía independiente a la que la Cámara de Comercio Internacional dedicó sus Uniform Rules for Contract Guarantees (1978) para la uniformización del texto de dichas garantías. Sin embargo, la enumeración aludida no tiene carácter exclusivo, pues otros tipos de garantía eran asimismo utilizados. Así, los contratos de ejecución de obra pueden incluir una garantía de retención, Retention money bond, substitutoria del importe a ser retenido de cada pago parcial hecho al contratista hasta la recepción definitiva de los obras. A su vez, la Maintenance bond, figura cercana a la anterior, es más específica de los contratos denominados «producto en mano» en los que el vendedor asume la obligación de asegurar el adecuado funcionamiento de la fábrica durante un cierto período de tiempo contra todo vicio o anomalía de la construcción de la fábrica o de la maquinaria que pudieran aparecer tras su recepción definitiva ${ }^{20}$.

Sin embargo, la versatilidad de las garantías independientes hace que no tenga particular interés su clasificación por relación al tipo de obligación garantizada, pues tal versatilidad hace que resulten utilizables para el aseguramiento de prácticamente cualquier clase de riesgo u obligación. Puede servir de ejemplo de su grado de flexibilidad una particular modalidad de garantía independiente utilizado en derecho marítimo, cuyo régimen no parece todavía claramente reconocido y definido: la carta de garantía por falta de conocimiento de embarque ${ }^{21}$. Otro ejemplo de la versatilidad de las garantías independientes puede apreciarse en el supuesto de la adquisición de una empresa, cuando no se adquieren únicamente activos sino los títulos representativos del capital social. El vendedor puede garantizar al comprador, mediante la entrega de una garantía por importe y plazo pactados, frente a las responsabilidades ocultas de índole financiera, fiscal o laboral, que pudieran pesar sobre la sociedad y que no hubieren sido detectadas por el examen de auditoría que, previsiblemente, habrá tenido lugar con an-

20 Cfr. Bertrams, op. cit., pp. 29-33; vid. la exposición de Poullet, art. cit., pp. 395397, acerca de las diferentes clases de garantía y sus posibilidades de utilización.

${ }^{21}$ El buque puede llegar a destino antes que el conocimiento de embarque. El destinatario o el transportista pueden tener razones para no esperar la llegada de este documento y efectuar la entrega de las mercancías. El transportista incurriría en responsabilidad si entregara las mercancías sin el correspondiente conocimiento de embarque. Por ello, debe disponer de una garantía de indemnización para el caso de que incurriera en tal responsabilidad, por lo que exige que este compromiso del destinatario sea cubierto por una garantía independiente. Acerca de tal uso de la garantía independiente, vid. REMOND-GouILLoud, La lettre de garantie pour absence de connaissement. Une institution en quete de qualification, Bulletin de Transport, 1986, p. 69. 
terioridad a la adquisición de las acciones. Una garantía independiente puede ser asimismo utilizada para asegurar el pago del precio de una compraventa de un terreno, o para asegurar la devolución del precio pagado, cuando la edificabilidad del terreno depende de la obtención de los pertinentes permisos y licencias administrativas inexistentes en el momento de la celebración del contrato de compraventa, y para el caso de que tales autorizaciones no fueran obtenidas.

En suma, la clasificación de las garantías independientes en atención a las obligaciones garantizadas presenta un interés secundario puesto que la versatilidad de dichas garantías hace que sean utilizables prácticamente para la cobertura de cualquier riesgo o el aseguramiento de cualquier clase de obligación ${ }^{22}$.

\section{Las modalidades de garantías independientes}

Las partes tienen plena libertad para la determinación de la modalidad de garantía cuya utilización acuerdan, sin restricción alguna en lo relativo a su importe o duración. No hay inconveniente en que una garantía independiente tenga limitaciones en cuanto a su importe o duración o, por el contrario, sea ilimitada, aun cuando un compromiso de duración indeterminada resulte de escaso interés al poder ser anulado unilateralmente; la hipótesis de una garantía independiente de importe ilimitado no parece concebible, pues implicaría la falta de parámetros para la medición de la obligación principal.

El carácter específico de las garantías independientes reside en la garantía que procuran al beneficiario en virtud del rigor de su fuerza coercitiva. El principio de inoponibilidad de excepciones fortalece la posición del beneficiario y hace más patente el rigor obligacional que recae sobre el garante. La garantía debe recibir ejecución si el beneficiario reclama su pago. La inoponibilidad de excepciones priva al garante de toda escapatoria. Este rigor es, sin embargo, susceptible de graduación. En la práctica se conocen principalmente tres variantes de garantías independientes.

\section{A) LA GARANTÍA INDEPENDIENTE SIMPLE A PRIMERA DEMANDA}

La forma más rigurosa de las garantías independientes, así como la más frecuente, es la garantía a primera demanda que debe ser hecha

22 Acerca de la mencionada versatilidad garantizatoria de las garantías independientes, cfr. CABRILlac y Mouly, op. cit., p. 333, donde los autores introducen un epígrafe titulado «la garantie de toute operation non decrite» y expresamente mencionan el caso de un banco garante de las deudas de un país en vías de desarrollo. 
efectiva en cuanto sea solicitado su pago, con lo que resulta discrecional para el beneficiario si éste la reclama dentro del período de vigencia previsto en el contrato. A título de criterio general, no es admisible la posposición de la ejecución, ni una prohibición de pago, ni puede ordenarse ninguna intervención judicial. Sólo el carácter manifiestamente abusivo de la reclamación puede fundamentar la negativa del garante al pago. En este supuesto, garante y ordenante quedan a expensas de la buena fe del beneficiario, aunque quepa recurso contra aquel caso de reclamación injustificada. La frecuente presencia en los contratos internacionales de cartas de garantía de rigor implacable obedece al hecho de que se asemejan, en cuanto a sus efectos, a la constitución de un depósito de garantía. Se puede comprender, pues, que el acreedor acepte substituir tal forma costosa de garantía por una garantía, por lo que exige que ésta le depare las mismas ventajas de accesibilidad y disponibilidad. Unicamente un compromiso de pago a primera demanda asumido por su propio banco puede responder a esta exigencia.

\section{B) LA GARANTÍA DOCUMENTARIA}

La reclamación del pago de la garantía puede estar subordinada, sin que ello le prive de su carácter independiente, a la presentación de determinados documentos especificados en la carta de garantía que condicionan y justifican dicha solicitud. Esta modalidad atenúa, según la naturaleza de los documentos exigidos, el riesgo de reclamación improcedente o abusiva de la garantía ${ }^{23}$. Los documentos justificativos pueden emanar de terceros si así lo pactaran las partes (vgr. un peritaje que demuestre la inejecución o deficiente ejecución; un informe emitido por un gabinete de estudios); o pueden emanar del propio beneficiario (vgr. facturas impagadas), siendo necesario que de tales documentos se desprenda la prueba o verosimilitud de la pretensión invocada. Este tipo de garantía parece recibir una menor utilización en los contratos internacionales. No existe $a$ priori ningún documento especialmente indicado para el cumplimiento de tal función. Son las partes quienes deben definir los documentos justificativos, lo que da lugar a la variedad de los documentos utilizados.

\section{C) LA GARANTÍA JUSTIFICADA A PRIMERA DEMANDA}

La garantía justificada a primera demanda, modalidad intermedia entre las citadas, parece recibir una utilización creciente. Es el resul-

23 Cfr. SiMLER, op. cit., p. 708. 
tado de la traducción literal de la expresión anglosajona justified request, denominación no desprovista de ambigüedad. En esta hipótesis, el beneficiario de la garantía debe «justificar» su reclamación, pero la justificación requerida emana del propio beneficiario sin la exigencia de otras pruebas. Puede ser suficiente la afirmación de que el contrato no ha sido ejecutado o lo ha sido de forma defectuosa. El garante no puede exigir pruebas de las afirmaciones del beneficiario y no puede proceder a su verificación ${ }^{24}$.

La diferencia entre esta forma de garantía y la garantía documentaria es clara ${ }^{25}$, pero no lo es tanto en relación a la garantía a primera demanda simple, porque la discrecionalidad en la reclamación de la garantía está atenuada de manera formal. En la práctica, la diferencia parece ser mayor puesto que, dado que el beneficiario debe indicar las razones justificativas de la reclamación de la garantía, su actuación ya puede no ser tan libérrima al comprometer su responsabilidad con sus afirmaciones y facilita la posterior acción del ordenante contra el beneficiario fundándose en la inexactitud de tales afirmaciones.

${ }^{24} \mathrm{La}$ CCI ha optado por el general carácter documentario de las garantías independientes, dentro de su tradicional pretensión de «moralizar» los comportamientos en el comercio internacional, tal como rezan la introducción a las URGC, 1978 y el preámbulo de las RUGD, 1992, Publicación CCI n. ${ }^{\circ} 458$, de forma que toda reclamación del pago de una garantía tendrá que ser documentada o justificada. Ello es lo que refleja el artículo 20 (a) de las RUGD: «Todo requerimiento de pago según los términos de la garantía será hecho por escrito y documentado, (junto con todos los demás documentos que puedan especificarse en la garantía) con una declaración escrita (tanto en el propio requerimiento como en un documento o documentos separados que lo acompañen y referidos en él) que especifique: i) que el ordenante ha faltado a su(s) obligación(es) según el/(los) contrato(s) de base o, en el caso de una garantía de licitación a las condiciones de la licitación, y ii) lo que haya incumplido el ordenante».

${ }^{25}$ Una sentencia de la Cour d'Appel de París, de 24 de noviembre de 1981, analizó las diferencias apreciables entre la garantía a demanda justificada y las modalidades antes mencionadas, afirmando que la expresión «a primera demanda justificada» no priva a la garantía de su carácter independiente en relación al contrato principal, sino que significa que el pago de la garantía está subordinado a una simple declaración detallada por parte del beneficiario, de acuerdo con la cual el contrato principal no habría sido debidamente ejecutado por el ordenante; en consecuencia, la reclamación de la garantía no exige juicio ni prueba del incumplimiento de sus obligaciones por el ordenante. Comentario de VAsseuR, en Rev. Trimestrielle de Droit Commercial, 1981, p. 813. El carácter no tan claro de la interpretación del término «justificada» hace que determinados autores sostengan otra interpretación, asimilándola a una garantía documentaria. La diferencia resulta todavía menor si el beneficiario debe adjuntar un escrito en el que afirma la inejecución total o parcial del contrato, sin estar obligado a precisar la naturaleza del incumplimiento; al respecto, cfr. MAтTout, Droit bancaire... cit., p. 200. 


\section{La garantía independiente y figuras afines}

La especificidad jurídica de las garantías independientes frente al tipo contractual de la fianza se fundamenta en la accesoriedad de ésta confrontada con el carácter principal e independiente de aquella, caracteres que son consecuencia de la función económica buscada y querida por las partes que quedaría defraudada y sería de imposible consecución sin tales características.

La anterior afirmación no es admisible para algún sector de nuestra doctrina. En tal sentido, CARRASCo PERERA ${ }^{26}$, afirma que «una consideración banalizada sobre las instituciones codificadas, un desmesurado gusto por la recurrencia a la atipicidad contractual y una precomprensión —agudizada entre nuestros autores mercantilistasde toda manifestación nueva del tráfico contractual requiere por ello mismo un tipo contractual nuevo, todo ello está conduciendo a un socavamiento de las normas del CC, que son preteridas por principio sin detenerse a considerar la necesidad de ello ni las consecuencias perturbadoras para el sistema que supone la creación incontrolada de tipos novedosos no sujetos a ninguna restricción de validez». El autor trata de establecer que la fianza no es un tipo rígido sino flexible, al que cabe reconducir prácticamente cualquier mecanismo que las partes imaginen para garantizar el pago de un tercero, y en especial la garantía independiente. El problema estriba en que el estudio así desarrollado termina por dibujar unos contornos de la fianza tan difusos ${ }^{27}$ que resulta casi imposible la definición del tipo de la fianza o la enunciación de un núcleo de normas que caractericen el tipo más allá de una genérica función de garantía ${ }^{28}$.

Por el contrario, LOUSSOUARN ${ }^{29}$ ha señalado que la garantía independiente es «una derivación de la fianza de la que toma en préstamo su técnica jurídica aunque se desprende de su carácter accesorio». La fianza dispone de una regulación legal que le atribuye determinados caracteres pudiendo decaer algunos de los cuales mediante pacto entre las

26 Cfr. Carrasco Perera, op. cit., p. 2.

27 Tal posición recibe la crítica generalizada de la doctrina española. Vid. al respecto, DíAz Moreno, Las garantías a primer requerimiento cit., p. 633; MARTínez CALCERRADA, art. cit, pp. 824-826; SÁNCHEZ CALERO-GuILARTE, El contrato autónomo de garantía, cit, pp. 95-105; ECHENIQUE GORDILlO, art. cit., pp. 155-158.

${ }_{28}$ Dicha tesis se enfrenta asimismo a las pautas generalmente seguida por la doctrina de otros países. Vid. Simler, op. cit., p. 677; VASSEUR, art. cit., p. 362; BerTRAMS, op. cit., p. 164.

${ }^{29}$ Cfr. Loussounar, Les suretés personnelles traditionnelles en droit international privé, en «Les Suretés», París, Feduci, 1984, p. 431. 
partes, posibilidad sin embargo que no alcanza a todos ellos, bien en razón de su carácter esencial sin el que no sería posible la apreciación del tipo de la fianza (vgr, oponibilidad de las excepciones derivadas de la obligación principal), bien fuere porque ello entrañaría contravención legal. A resultado parecido al de la figura de las garantías independientes se podría haber llegado, quizá, mediante la renuncia al carácter accesorio de la fianza o mediante la renuncia a la oponibilidad de las excepciones derivadas del contrato principal, pero tal obligación, configurada sin tales rasgos o caracteres esenciales, aun cuando probablemente constitutiva de una garantía personal, simplemente hubiera conservado la denominación de fianza sin que fuera en ella posible la apreciación de ningún grado de especificidad conceptual, de forma que no hubiera resultado aceptable tal desnaturalización del tipo de la fianza. En la misma línea, expone MouLY ${ }^{30}$, las obligaciones contenidas en una garantía independiente resultan mucho más apremiantes que la fianza. Su evolución y desarrollo podrían ser la consecuencia de un exceso de protección legislativa y judicial para con la fianza. La historia y el derecho comparado, muestran que, cuando la fianza se debilita como consecuencia de un aumento en el grado de protección legislativa, la práctica busca otras formas de garantía personal, mucho más rigurosas.

Sin embargo, la contraposición entre fianza y garantía independiente no es idea aceptada sin reservas por todos los ordenamientos jurídicos. Así, la figura de la fianza a primera demanda ha sido aceptada por los tribunales alemanes de acuerdo con la tendencia del derecho alemán al ensanchamiento del marco tipológico de la fianza, aunque ello ha concitado la crítica de una parte de la doctrina ${ }^{31}$.

Por el contrario, cabe asumir la postura contraria y afirmar su improcedencia como lesiva para la seguridad y certidumbre del tráfico económico y comercial internacional, y ello por razones diversas: en primer lugar, situando la cuestión en términos conceptuales, reconducir e insertar la figura de las garantías independientes y otras obligaciones fideusorias en el tipo de la fianza, a semejanza de la doctrina alemana e italiana, implica privar prácticamente de cualquier rasgo diferenciativo

30 Mouly, «Pour la liberté des garanties personnelles», en Rev. Banque, 1987, p. 1.166.

31 Cfr. crítica de RoHmert, «Le cautionement á premiére demande en droit allemand: une sureté hybride», en Rev. de Droit Bancaire et de la Bourse, 1994, acerca de la admisión por los tribunales alemanes de la fianza a primera demanda, p. 125. Con ello se muestra de acuerdo CARrasco Perera, op. cit., pp. 33-34, quien defiende la idoneidad del tipo de la fianza para albergar en su seno la generalidad de las figuras fideusorias por lo que sostiene la admisibilidad de la fianza a primera demanda y la posibilidad de su incardinación en el tipo de la fianza. 
a la fianza, pues ésta quedaría construida de forma tan amplia que sería muy difícil la más mínima precisión de sus contornos conceptuales ${ }^{32}$. En segundo lugar, las garantías independientes han encontrado su origen en las prácticas del comercio internacional y es en el comercio internacional donde siguen recibiendo una mayor utilización, habiendo llegado a conseguir una substancial caracterización uniforme. En suma, se debe hacer un esfuerzo por construir y considerar las garantías independientes desde puntos de vista transnacionales, en correspondencia con su actual conceptualización y utilización. La admisión de la figura de la fianza a primera demanda iría contra tal propósito, pues ello implicaría la remisión en cada ocasión a un ordenamiento jurídico interno, lo que haría imposible una caracterización uniforme de las garantías independientes. Por último, la certidumbre del tráfico internacional se resentiría si se construyeran las garantías independientes, no ya únicamente desde una perspectiva interna o nacional, sino por relación al tipo de la fianza existente en cada ordenamiento interno. El beneficiario de la garantía, por hipótesis extranjero al ordenamiento en el que la garantía ha sido emitida, siempre podría albergar alguna duda acerca de la garantía recibida, en particular acerca de las excepciones oponibles por el garante. Todo ello parece indicar que la admisión de la fianza a primera demanda, además de sembrar la duda acerca de su utilidad o de la aportación que pueda significar para las necesidades del tráfico internacional, puede resultar lesiva para la certidumbre y seguridad especialmente necesaria en las relaciones internacionales ${ }^{33}$.

Su clara diferenciación frente al tipo de la fianza, según expone MARTínEZ CALCERRADA, impide el recurso a la normativa reguladora de la misma, pues dicha normativa es substancialmente tributaria de su carácter de accesoriedad, aun cuando tal profunda diferencia en cuanto a su naturaleza jurídica no impide su consideración conjunta como garantías personales, por lo que la analogía no puede ser excluida en relación a aquellos aspectos que no fueren directa consecuencia de sus opuestos caracteres de accesoriedad o independencia ${ }^{34}$. Lo específico del contrato de garantía independiente impide igualmente, al menos en principio, la inspiración en el régimen regulador de otros tipos contrac-

32 Crítica de Díaz Moreno, Las garantías a primer requerimiento, cit., p. 633.

33 ROHMERT, art. cit., p. 125.

34 Cfr. Martínez Calcerrada, art. cit., p. 824: el autor se basa en la profesionalidad del garante para sostener la exclusión de la aplicación de la normativa reguladora de la fianza a las garantías independientes: «La intervención generalizada del garante profesional en la emisión de las garantías hace que las reglas de la fianza resulten inoportunas... La posibilidad de oponer excepciones a la reclamación del beneficiario representa un verdadero obstáculo indeseado... por impedir su buen hacer profesional». 
tuales nominados ${ }^{35}$ con los que cupiera la apreciación de elementos comunes. En realidad, únicamente la analogía con la figura del crédito documentario ha proporcionado algunas soluciones en materia de garantías independientes.

En la actualidad, resulta general el pronunciamiento doctrinal ${ }^{36}$ en favor de la aceptación de la diferenciación conceptual jurídica de las garantías independientes frente a otros tipos jurídicos acuñados por los ordenamientos jurídicos y se señalan las singularidades y diferencias de la figura de las garantías independientes ${ }^{37}$.

\section{La naturaleza juridica de la garantia independiente}

La novedad de la noción de garantía independiente, la imprecisión de la terminología y la dificultad de la distinción entre la fianza y esta nueva especie de garantía personal, imponen el análisis de su naturaleza jurídica y la búsqueda de sus elementos específicos constitutivos.

\section{Las relaciones involucradas y la preeminencia de la relación de garantía}

Las garantías independientes dan lugar a un entramado obligacional complejo, en el que se registra la presencia de obligaciones diversas entre sí relacionadas.

35 Coca y Flaquer, art. cit., pp. 474 y ss., analizan las causas que explican la confusión en la práctica en referencia a supuestos de nuestro ámbito jurídico y a diversas sentencias del TS allí citadas.

36 Afirmación hecha por la mayor parte de la doctrina. Cfr. SiMLER, op. cit., p. 710; Bertrams, op. cit., p. 40; Poullet, art. cit., p. 413; Dohm, op. cit., p. 61; en la doctrina española, SÁnChEZ-CALERo GuILARTE, El contrato autónomo de garantía, cit. p., 107.

37 Asimismo, se acepta su diferenciación frente al seguro de crédito. En este último, el asegurador se obliga a indemnizar al asegurado las pérdidas finales que experimentase a consecuencia de la insolvencia definitiva de sus deudores. Es decir, se asegura directamente al asegurado frente al daño patrimonial derivado de la insolvencia definitiva. El riesgo asegurado ya no es un incumplimiento del tomador del seguro, sino el valor que pueda alcanzar el perjuicio que se derive de esa insolvencia definitiva del deudor. Vid. EMBID IRUjo, $\mathrm{El} \mathrm{se-}$ guro de caución. Régimen jurídico convencional y naturaleza jurídica, La Ley, mayo de 1988 , p. 1. Tampoco plantea problema su diferenciación frente al crédito documentario, KoZOLCHYK, Bank guarantees and letters of credit, cit. p. 14. Por lo que se refiere a las cartas de patrocinio, mientras que el garante emisor de una garantía independiente asume una obligación propia frente al beneficiario quien podrá exigir directamente el cumplimiento de dicha obligación, en las cartas de patrocinio el emisor de la carta de patrocinio promete que será su filial quien reembolsará su deuda, sin que exista una obligación substitutoria para el emisor de la carta de patrocinio. Vid. DuQue, Las cartas de patrocinio, en «Nuevas entidades, figuras contractuales y garantías en el mercado financiero», Madrid, 1990, pp. 719-777. 
La primera relación es la existente entre exportador e importador, relación subyacente garantizada. Su posible contenido puede resultar muy variado, por lo que carece de relevancia el tipo o clase de contrato celebrado entre las partes. En cumplimiento de las obligaciones asumidas en el contrato subyacente, el comprador solicita que el vendedor le procure una garantía independiente emitida por un garante de solvencia, normalmente una institución financiera, hasta una cierta cantidad acordada por las partes y por determinado plazo de vigencia, estableciendo igualmente las condiciones bajo las que podrá reclamar del garante el pago de la garantía. El ordenante de la garantía no suele disponer de ningún margen de discrecionalidad en lo tocante al contenido de la garantía, el cual suele obedecer a cláusulas previamente redactadas por el beneficiario que, asimismo, pueden haber quedado incluidas en el contrato principal. El vendedor debe así dar cumplimiento a una prestación contractual con carácter previo ${ }^{38}$. Es cierto que la garantía es emitida como aseguramiento, pero ello no permite la conclusión de que la emisión de la garantía constituye una obligación contractual secundaria. Por el contrario $^{39}$, la garantía desempeña una función esencial pues debe asegurar al comprador la correcta ejecución del contrato principal, o si ésta no se produjera, debe asegurar el pago a primera demanda. La obligación de emisión de la garantía independiente debe, pues, ser considerada como una obligación contractual principal del vendedor.

La segunda relación jurídica presente en el entramado obligacional es la relación entre ordenante y garante ${ }^{40}$. Normalmente será el deudor principal el que se dirija al banco solicitándole la garantía, de manera que surge entre ambos una relación de mandato o comisión. El garante puede asumir el riesgo de impago de las sumas pagadas en nombre del ordenante.

En tercer lugar, la relación entre beneficiario y garante es la consecuencia de la relación de mandato concluida entre ordenante y garante, ya que el banco ha asumido el compromiso de pagar al beneficiario una cantidad pactada con el ordenante supuesto el cumplimiento de unas condiciones determinadas, por lo que la relación entre garante y beneficiario es un negocio de ejecución del mandato entre ordenante y garante. Esta relación liga al garante con el beneficiario quedando aquel

38 Rives-Lange y Contamine-Raynaud, Droit bancaire, cit. pp. 725-726.

39 Cfr. DohM, op. cit., pág. 75.

40 Cfr. Echenique-Gordillo, art. cit., pp. 154-155; SÁnchez-Calero Guilarte, El contrato autónomo de garantía cit., pp. 147-252. 
obligado a pagar a éste una suma de dinero determinada a su primera demanda una vez cumplidas las condiciones contempladas en la carta de garantía ${ }^{41}$.

Lo determinante de esta relación en el entramado obligacional, de la que se deriva su preeminencia, se pone de manifiesto en el vínculo jurídico que une a garante y beneficiario, que resulta ser independiente de la relación subyacente concluida entre ordenante y beneficiario, es decir, vendedor y comprador. Los requisitos, presupuestos y caracteres de la obligación del garante son propios y exclusivos de ella y vienen determinados en la carta de garantía, sin quedar afectados por las vicisitudes que pudieran afectar a la formación o la ejecución del contrato subyacente. Ello implica que la relación entre garante y beneficiario se caracteriza esencialmente por la inoponibilidad de aquellas excepciones que pudieran derivarse de la relación subyacente, de forma que el garante no podrá oponer las excepciones relativas a la validez o al cumplimiento del contrato garantizado o las referentes a la extinción de la obligación del ordenante, e igualmente tampoco serán oponibles las excepciones derivadas de la relación entre ordenante y garante.

En consecuencia, con carácter general, el garante podrá negarse al pago de la garantía únicamente en virtud de excepciones derivadas del texto propio de la garantía que constituye, según la exposición de CERDÁ ${ }^{42}$, la expresión de la voluntad del garante y el límite de la obligación que asume. La carta de garantía delimita los derechos del beneficiario quien no podrá exigir nada del garante si no es de conformidad con las condiciones previstas en el propio texto de la garantía.

Igualmente, pero con carácter excepcional, el garante podrá negarse al pago de la garantía en el supuesto de reclamación manifiestamente abusiva o fraude palmariamente evidente por parte del beneficiario cuya apreciación resultará siempre problemática pues $^{43}$, debe encontrarse «un justo equilibrio entre el derecho del beneficiario a reclamar el pago de la garantía, incluso cuando se discuta entre las partes el cumplimiento de la obligación subyacente y la injusticia que representaría reconocer al beneficiario ese derecho a percibir el cobro de la garantía caso de que su mala fe fuera evidente para el garante». La apreciación de esta excepción será aún más delicada para el garante quien,

41 Vid. la exposición de Martínez CalCERRADA, art. cit., pág. 824.

42 Cfr. Cerdá Olmedo, op. cit., p. 94.

43 Cfr. la St. del Trib. Comm. de Bruselas, de 23 de diciembre de 1980, en Rev. Banque, 1981, p. 627. 
de no advertir la evidente mala fe del beneficiario, padecerá el riesgo de que el ordenante quede exonerado de su obligación de reembolso para con el garante.

Por último, en ocasiones, el banco emisor de la garantía o garante de primer grado, habrá actuado dando cumplimientos a las instrucciones recibidas de otro banco, normalmente el banco del ordenante de la garantía ${ }^{44}$. Este último banco, que es realmente quien pone en marcha el mecanismo de la garantía, ordena a su corresponsal la emisión de la garantía a favor del beneficiario, para lo cual, a su vez, garantiza al banco emisor de la garantía otorgándole su contragarantía, de manera que los riesgos asumidos por el banco emisor quedan contragarantizados por el banco mandante. La contragarantía es la garantía exigida por el garante de primer rango, directamente comprometido frente al beneficiario designado por el librador, para asegurarse el reembolso de aquello que tuviera que pagar en ejecución de su propio compromiso. En las garantías independientes internacionales, esta combinación de garantía y contragarantía es frecuente, y obedece al hecho de que quien contrata un suministro de bienes o servicios quiere una garantía accesible y equivalente a un depósito de dinero, por lo que, en última instancia, sólo el compromiso de un banco de su propio país puede responder a estos criterios $^{45}$.

\section{Los caracteres de las garantías independientes}

\section{A) LA INDEPENDENCIA DE LA GARANTÍA}

El carácter de independencia hace referencia a lo más esencial y específico de la garantía independiente, de significación similar al carácter accesorio de la fianza, y desempeña una función esencial en la determinación de la calificación y de los efectos del compromiso. El compromiso del garante contiene una deuda nueva independiente de aquella que se quiere garantizar. La independencia significa, por tanto, que el garante asume un nuevo compromiso a título principal, sin obligarse al pago de la deuda del deudor principal como sucede en la fianza, sino que asume el compromiso de pagar una cierta suma libremente determinada por las partes. Aunque es posible que la garantía se adapte a los límites y contornos de la obligación del deudor, la mayoría

44 Vid. especialmente Bertrams, op. cit., pp. 135 y ss.; igualmente, Simler, op. cit., pp. 695-699.

45 SiMLER, op. cit., p. 696; DoHM, op. cit., pp. 47-49 y 139-142. 
de las veces la garantía responde a una obligación principal en dinero y representa una fracción del valor de esta prestación ${ }^{46}$.

La independencia significa que la garantía no está sometida a la norma aplicable a la fianza según la cual ésta no puede exceder de aquello que es debido por el deudor afianzado ni puede contener condiciones más onerosas.

La independencia implica que la validez, duración, extensión, ejecución o inejecución de la obligación garantizada o de la obligación de garantía no tiene incidencia sobre la otra ${ }^{47}$. Ello refuerza la función de garantía, que es precisamente el objetivo deseado. En consecuencia, la independencia se traduce esencialmente en la inoponibilidad por el garante de toda excepción relativa al contrato subyacente ${ }^{48}$.

\section{a) La independencia de la garantía y su desconexión del resto de relaciones}

La independencia de la garantía en la relación entre garante y beneficiario se manifiesta en dos aspectos: en primer lugar, la relación no se ve afectada por la relación de mandato o comisión existente entre el banco y el ordenante; en segundo lugar, la obligación de pago del banco y el derecho del beneficiario al cobro quedarán determinados por

46 Es la afirmación generalmente realizada por la doctrina. En tal sentido, BERTRAMS, op. cit., pp. 173 y ss.; HORN y WYMEERSCH, Bank guaranteees, Stand-by letters of credit and performance bonds in International trade, cit. pp. 455 y ss. La idea expresada es sostenida por la generalidad de la doctrina de los diversos países: CABRILlaC y Mouly, op. cit., pp. 346 y ss.; CHATTERJEe, The independence of contracts of guarantee... cit. p. 113; Portale, Nuovi sviluppi... cit., pp. 176 y ss.; ECHENIQUe, art. cit., pp. 147-163; SÁNCHEZ CAlero Guilarte, El contrato autónomo de garantía, cit., p. 296.

47 SiMLER, op. cit., pp. 684-687.

${ }^{48}$ Las vicisitudes que afectan al contrato subyacente pueden ser diversas. En ocasiones, el ordenante se muestra en desacuerdo con el montante adeudado al beneficiario. Cfr. Dalloz, J., 1981, 336, comentario de VASSEUR. El caso enjuiciado por la Cour d'Appel de París, el 29 de enero de 1981, se refería a una garantía de ejecución dada al contratista por un subcontratista. Este sostuvo que el montante solicitado no guardaba proporción con el perjuicio sufrido por el contratista, argumento aceptado por el banco quien se negó al pago. La Cour d'Appel respaldó la obligación de pagar, porque el banco estaba desconociendo el carácter independiente de la garantía. St. Cour d'Appel de Riom, 14 de mayo de 1980, D. 1981, J., 336, comentario de VASSEUR. El Tribunal afirmó que «el contrato de garantía independiente debe ser apreciado en sí mismo y al margen de las vicisitudes que pudieran afectar a la operación mercantil, sin consideración a las maniobras (del beneficiario) producidas con ocasión de un contrato anterior, o incluso su mala fe no pueden interferir en el contrato...». Igualmente, Trib. Gde. Inst. París, 11 de julio 1980 (D. 1981, J., 336): «La garantía a primera demanda presenta un carácter incondicional, independiente de las diferencias que pudieran existir entre el comprador y el vendedor». 
los términos y condiciones establecidas en la garantía y no por referencia a la relación subyacente.

El garante tampoco podrá esgrimir la modificación del objeto de la operación subyacente producida tras el nacimiento del compromiso de garantía, salvo si la garantía hiciera referencia explícita al objeto de la operación subyacente ${ }^{49}$.

El garante deberá proceder al pago en el supuesto de que los términos de la garantía hubieran sido cumplimentados sin poder esgrimir defensa alguna emanada de la relación subyacente, lo que resultaría posible para un fiador. La determinación del incumplimiento por el deudor principal o las diferencias a este respecto no son cuestión entre el banco y el beneficiario. Para ostentar legitimación al objeto de obtener un pago, el beneficiario sólo tendrá que satisfacer los términos de la garantía y no necesitará proceder a otra demostración del incumplimiento.

El garante asume el riesgo de impago de las sumas pagadas en nombre del ordenante, sin que sea relevante la causa del impago. El garante no puede hacer valer ni la retractación del ordenante, ni la insolvencia de aquel sobrevenida tras la emisión de la garantía, ni su ruptura de relaciones con el ordenante, ni tan siquiera el hecho de que al ordenante le resultara imposible el reembolso ${ }^{50}$

La afirmación de la independencia de la garantía en cuanto contrato entre el banco y el beneficiario frente al contrato principal o frente a la relación de mandato sólo es realmente posible a partir de su interdependencia funcional. No cabría hablar de plena independencia si estas relaciones fueran completamente inconexas entre sí, pues es precisamente la propia interdependencia apreciable entre ellas la que otorga sentido y significado al principio de independencia. Las diversas relaciones se encuentran relacionadas entre sí en determinados aspectos de manera funcional y substantiva, y al mismo tiempo son independientes entre sís1.

\section{b) La paralela independencia de la contragarantía}

Del mismo modo que la garantía de primer grado es independiente, las contragarantías son igualmente independientes, y ello no sólo en relación al contrato subyacente, sino también en relación a cada uno de

$49 \mathrm{Al}$ respecto, Poullet, art. cit., pp. 421 y 422; VILLEREY, art. cit., p. 272; GAVALDA y Stoufflet, La lettre de garantie, cit., pp. 299 y ss. Sin embargo, la afirmación no es completamente pacífica; así, en contra, VASSEUR, Rapport de synthése... cit., pp. 340 y 341, quien no la respalda caso de modificación substancial, DubISSON, Le droit de saisir... cit. pp. 423 y ss.

50 Cfr. VASSEUR, Rapport de synthése, cit. p. 347.

51 Bertrams, op. cit., pp. 161-164. 
los eslabones de la cadena, El principio de la autonomía de los diferentes eslabones resulta claramente afirmado por la jurisprudencia. En un caso en el que, sobre la garantía independiente de primer grado, se habían insertado tres contragarantías sucesivas, la Cour de Cassation declaró que, «en la cadena de contragarantías, cada compromiso es independiente de los demás y del contrato subyacente» ${ }^{52}$.

c) Independencia e inoponibilidad de excepciones derivadas del contrato subyacente

El corolario de la independencia estriba en la inoponibilidad de excepciones, lo que significa que el garante no puede oponer al beneficiario otras excepciones que las derivadas del propio contrato de garantía. Si la garantía es pagadera a su primera demanda, lo que suele ser el caso más habitual, el garante no puede demandar explicación alguna, y se verá en la obligación de hacer frente al pago de la garantía aunque tuviera conocimiento de la posible nulidad del contrato principal, o de su resolución, o de su completa ejecución, o de su extinción por causa cualquiera de extinción de las obligaciones, tales como la novación, compensación, etc. Tal rigor puede parecer en algún grado sorprendente, pues obliga al garante a pagar cuando la licitud o nulidad del contrato es dudosa, o a pesar de que ordenante hubiera dado cumplimiento a los compromisos garantizados. Al mismo tiempo, tal rigor provoca un riesgo de abuso considerable, aun cuando es la consecuencia del carácter de independencia de la obligación del garante.

La jurisprudencia ha intentado en ocasiones proyectar la regulación legal de la fianza sobre la aplicación estricta de la fuerza obligatoria del contrato. La única matización finalmente admitida, que no constituye auténtica derogación de la regla de la inoponibilidad de excepciones, estriba en la reclamación manifiestamente abusiva del pago de la garantía. En otro caso, el garante deberá cumplir su compromiso. El garante $u$ ordenante, en su intento de impedir el pago de la garantía, no pueden oponer frente al beneficiario: $1^{\circ}$ ) ni la nulidad del contrato subyacente; $2 .^{\circ}$ ) ni su resolución o anulación; $3 .^{\circ}$ ) ni la inejecución del contrato subyacente por acto o falta del acreedor mismo, o por fuerza mayor; $\left.4 .^{\circ}\right)$ ni la ejecución por el deudor garantizado de la mayor parte o de la totalidad de sus obligaciones; $5^{\circ}$ ) ni la compensación entre el monto de la garantía y una deuda del beneficiario para con el orde-

52 St. Trib. de Casation Comm, de 20 de noviembre de 1985, Soc. Dipra c. Banque Vernes et Commerciale de Paris, en Dalloz, 1986, J, p. 213, con comentario de VASSEUR. 
nante; $\left.6 .^{\circ}\right)$ ni la cesión del contrato subyacente por el ordenante o por el beneficiario de la garantía ${ }^{53}$.

\section{B) El CARÁCter unilateral de La garantía}

El compromiso asumido por el garante de pagar una suma de dinero determinada al beneficiario de la garantía a solicitud de éste, simple o condicionada, debe entenderse como un compromiso unilateral, aun cuando tal característica de unilateralidad no recibe un respaldo doctrinal unánime.

La tesis del compromiso unilateral fue inicialmente defendida ${ }^{54}$ en relación a los créditos documentarios irrevocables y recibió el respaldo de un sector de la doctrina. Sin embargo, el nacimiento de una obligación por la voluntad unilateral del garante es asimismo criticado por otro sector de la doctrina. Garante, exportador e importador participan, conjunta y conscientemente, en la formación de un mecanismo tripartito conocido con efectos predeterminados y, en él, sus voluntades se encuentran efectivamente. Para este sector doctrinal, la idea de contrato bilateral explica mejor la realidad de esta operación que la doctrina del acto unilateral ${ }^{55}$.

En las doctrinas de inspiración germánica, es general la afirmación del carácter unilateral de la garantía independiente ${ }^{56}$. Asimismo, para la doctrina italiana, la garantía bancaria a primera demanda debe ser considerado como un contrato unilateral innominado ${ }^{57}$. Por lo que a la doctrina anglosajona se refiere, GUTTERIDGE y MEgRAH apuntan que se debe buscar un fundamento sobre el que apoyar la idea de la existencia de un contrato a partir del momento en que la emisión del crédito documentario es comunicada al vendedor. Sin embargo, los citados autores apuntan que subsiste la dificultad consistente en que el crédito, en un primer momento, es simplemente una oferta que tiene que ser aceptada

53 Son las consecuencias primordiales cuya aceptación no siempre ha sido pacífica; vid. jurisprudencia al respecto de los tribunales franceses en VASSEUR, Dix ans de jurisprudence... cit. y referencias jurisprudenciales de los tribunales de diversos países allí citados; BERTRAMS, op. cit., pp. 161-165; cfr. especialmente el análisis de SIMLER, op. cit., pp. 685687.

54 Vid. al respecto HeNEN, «Le crédit irrévocable», en Rev. Banque, 1952, p. 458; el argumento es explicado extensamente por VELU, en el debate de las ponencias del Coloquio de Tours, 19 y 20 de junio de 1980, en «Les garanties bancaires dans les contrats internationaux», cit., pp. 423-424.

55 Principalmente, Poullet, art. cit., pp. 395 y ss.; su tesis es substancialmente seguida entre nosotros por CERDÁ OlMEdo, op. cit., pág. 46.

56 CANARIS, op. cit., pp. 591 y ss.; DoHM, op. cit., pp. 74-75.

57 MAZZONI, Les garanties bancaires en droit italien, cit. p. 292. 
por el beneficiario antes de que pueda apreciarse la existencia de un contrato. La jurisprudencia británica, por el contrario, parece inclinarse por el reconocimiento de su carácter unilateral al calificarlas como promesas de pago ${ }^{58}$.

En la doctrina francesa, aun cuando tanto el carácter unilateral de la garantía independiente como su carácter bilateral o contractual reciben apoyos, parece ser la consideración de la garantía independiente como relación bilateral la que goza de mayoritario respaldo ${ }^{59}$.

a) La voluntad unilateral como fuente de obligaciones en el sistema español

Nuestra tradición jurídica no ha sido favorable a la admisión de la obligatoriedad de la promesa unilateral, aun cuando siempre se han aceptado excepciones determinadas al respecto. Un sector de la doctrina $^{60}$ ha afirmado que no hay base absolutamente clara en nuestro derecho para reconocer la fuerza obligatoria de la promesa unilateral que no es objeto de aceptación, particularmente en atención al hecho de que el artículo 1.089 del CC no menciona la voluntad unilateral entre las fuentes de las obligaciones. Sin embargo, tras la afirmación mencionada, es generalmente apuntado que tampoco se registran obstáculos insuperables para su construcción técnica, de todo lo cual se siguen posiciones encontradas en la doctrina española ${ }^{61}$.

La doctrina civilista parece admitirla excepcionalmente. A juicio de DíEz PICAZO ${ }^{62}$, la solución debe ser matizada, pues «en principio, cabe

58 Cfr. Gutteridge y Megrah, The law of bankers' commercial credits... cit., p. 24. Más adelante, pp. 28-29, los autores hacen referencia a la teoría de la oferta y de la aceptación y a la naturaleza contractual de la carta de crédito sin otras precisiones acerca de la forma y momento de nacimiento del contrato. Lord DenNiNG dedujo del examen de las obligaciones del garante que «la garantía de ejecución tiene un régimen similar a las cartas de crédito» y también afirmó: «estas garantias de ejecución son virtualmente títulos a la orden pagaderos a la vista», Edward Owen Engineering Ltd. vs. Barclays Bank International Ltd. en apelación (1977), 3, WLR, 734.

59 Cabrillac y Mouly, op. cit., p. 331. Dentro del derecho francés en contra, sosteniendo el carácter unilateral, VASSEUR, Rapport de synthése... cit., p. 332.

${ }^{60}$ Cfr. la exposición de Albaladejo, Instituciones de Derecho civil, 5. a edición, Barcelona, 1980, p. 614; asimismo, LACRUZ BERDEJO, Elementos de derecho civil, Barcelona, Bosch, 1980, tomo II, pp. 75 y ss.

61 No aprecia especiales obstáculos para ello Gullón BALLESTEROS, Curso de derecho civil. El negocio jurídico, Madrid, Tecnos, 1968, pp. 27 y ss. De igual opinión es CASTÁN TOBEÑAS, Derecho civil español, común y foral, 13. a edición, Madrid, Reus, 1973, tomo III, pp. 98-102.

62 Díez Picazo, Fundamentos del derecho civil patrimonial, Madrid, Tecnos, 1983, pp. 66 y ss.; pp. 98 y ss.; pp. 389 y ss.; pp. 566 y ss. 
admitir que la declaración unilateral de voluntad del deudor es justo fundamento de un posible ejercicio por el acreedor de un derecho de crédito en todos aquellos casos en que la aceptación pueda presumirse. Por su parte, PUIG BRUTAU ${ }^{63}$ pone de relieve la influencia del factor social de la protección de la confianza en el problema de la fuerza vinculante de las declaraciones unilaterales de voluntad, poniendo de relieve que «lo declarado unilateralmente puede haber influido en la conducta ajena, y en la medida en que haya sucedido así, puede ser necesario proteger la confianza depositada en la apariencia. Si la relación jurídica entre los intereses de dos personas no brota de lo declarado por una y otra, puede brotar, no obstante, de la conducta de ambas en su recíproca influencia. Como un fundamental postulado de política jurídica, aparece una vez más la necesidad de proteger la confianza depositada en lo aparentado por la declaración».

La doctrina mercantilista ${ }^{64}$ juzga imposible negar a la voluntad unilateral la fuerza creadora de obligaciones, de manera que, aun cuando no hay coincidencia acerca de si es considerable como fuente general de obligaciones, sí hay tal coincidencia en la afirmación de que lo es en ciertos casos. «Por añadidura, señala LANGLE, se da el hecho de que no pocas relaciones que tradicionalmente eran tenidas por contractuales, ha revelado el progreso científico que son más propiamente unilaterales: las cambiarias, por ejemplo. En suma, ha ido extendiéndose en la mente de los juristas y ha dejado de ser demasiado limitada la idea de aplicar esta nueva doctrina en lo comercial.» Los negocios jurídicos unilaterales, prosigue el mencionado autor, realizan en el tráfico mercantil dos funciones del mayor interés, pues sirven para regular y definir relaciones jurídicas preexistentes (vgr, denuncia, denegación, protesto, deje de cuenta etc.), o para destacar de una de ellas (de una compraventa o de una cuenta corriente) un derecho de crédito, a fin de darles aptitudes para circular autónomamente en un título, y añade que en modo alguno quiere ello decir que sólo desempeñen esas dos funciones, sino que hay casos que no suponen la preexistencia de una relación jurídica, sino que la crean. Y, por su parte, afirma GARRIGUES que «la realidad del tráfico muestra que, en Derecho Mercantil, no es el contrato la única fuente de obligación, sino que lo es también la declaración de voluntad unilateral y la declaración plurilateral manifestada en el acto conjunto, que tampoco es contrato».

63 Cfr. Puig Brutau, Fundamentos de Derecho civil, tomo I, 2. ${ }^{\circ}$, 2. $^{\text {a }}$ ed., Barcelona, 1976, pp. 45-48.

${ }^{64}$ Garrigues, Contratos bancarios, Madrid, 1975, 2. a edición, pp. 612; Langle, Curso de Derecho Mercantil, Barcelona, Bosch, 1959, tomo II, pp. 36-39. 
Por su parte, la STS de 13 de noviembre de $1962^{65}$ declaró que, aun cuando el artículo 1.089 del Código Civil no enumera las declaraciones de voluntad unilaterales entre las fuentes productoras de las obligaciones, tampoco contiene norma explícita que las prohíba terminantemente, y de su comparación con otros preceptos, como los artículos $1.158,1.330,1.087$ de dicho cuerpo legal, y 587 y 789 , entre otros, del Código de Comercio, se llega a la conclusión de que determinados supuestos pueden dar origen al nacimiento de un título que las legitime y obligue al deudor a su cumplimiento. Doctrina ésta reiterada por la STS de 30 de septiembre de $1975^{66}$, la cual, sin añadir nuevas consideraciones, viene a recoger la doctrina favorable a la voluntad unilateral como fuente, al afirmar:

«Aun cuando el artículo 1089 del Código Civil no enumera las declaraciones unilaterales de voluntad entre las fuentes productoras de las obligaciones, tampoco contiene ninguna norma que las prohíba explícita y terminantemente, razón por la cual... la jurisprudencia de esta Sala las ha admitido... como creadoras del nacimiento de un título a favor de los sujetos a quienes van dirigidas, entendiendo que deben obligar a su cumplimiento a los que las emitieron por reflejar su voluntad e intención de asumir los deberes apreciados...»

\section{b) El carácter unilateral de la garantía independiente en el Derecho español}

Por lo que a la doctrina española se refiere, no es pacífico tal carácter de unilateralidad de la garantía, lo que quizá sea consecuencia de las dudas expresadas por la doctrina en orden a la admisibilidad de la declaración unilateral de voluntad como fuente de obligaciones en nuestro derecho, y ello lleva a algún autor ${ }^{67}$ al pronunciamiento a favor

65 El TS parece aceptar la voluntad unilateral como fuente de obligaciones, a pesar de las críticas doctrinales antes apuntadas. La STS, de 13 de noviembre de 1962 (Rep. Aranzadi, 1962, n. ${ }^{\circ}$ 4.288) afirma: «Pese a la doctrina contenida en las sentencias de esta Sala de 25 de abril de 1924 y 1 de diciembre de 1955 (Rep. Jur. n. ${ }^{\circ} 3.601$ ), las de 31 de octubre de 1924, 17 de octubre de 1932 (Rep. Jur. n. ${ }^{\circ}$ 722) y 10 de enero de 1946 (Rep. Jur. n. ${ }^{\circ}$ 1.714) expresan que emitida la declaración de voluntad con ánimo de obligarse una persona a otra a título de disposición, se genera un derecho de crédito a favor de la designada por reflejar la voluntad del promitente y su consciente intención de asumir el deber de cumplir lo ofrecido, doctrina que no es posible dejar de tener presente cuando el acto unilateral del oferente va seguido de la aceptación del interesado (...)». Albaladejo, Instituciones de Derecho civil, cit. p. 614, afirma que «la jurisprudencia del TS es confusa, contradictoria e intermitente».

66 Rep. Aranzadi, 1975, tomo XLII, vol. II, n. 3.408.

67 Cerdá Olmedo, op. cit., pp. 41-47. 
del carácter bilateral de la garantía haciéndose eco de los pronunciamientos de la doctrina francesa.

Por su parte, para GARRIGUES ${ }^{68}$ y en relación al crédito documentario, la obligación del banco de pagar nace de un acto unilateral que consiste en la emisión del instrumento. Por tanto no necesita la aceptación del beneficiario para ser vinculante. Sin embargo, el citado autor parece apuntar a continuación un cierto atisbo de bilateralidad, al sugerir que el consentimiento del beneficiario ha sido previamente prestado, pues «es cierto que esta aceptación no es necesaria, pero no se olvide que ha sido dada anticipadamente por el vendedor, al imponer en el contrato de compraventa el deber de buscar un banco que asuma la obligación de pagar».

Cabe apuntar que el consentimiento otorgado por el beneficiario en el momento de negociar las condiciones del contrato subyacente no lo es en referencia a la garantía como tal, sino que se trata de un consentimiento a una de las obligaciones que forman parte del contrato subyacente, cual es la obligación, normalmente impuesta por el beneficiario (comprador), de que le sea entregada una garantía por el ordenante. De esta forma, el consentimiento anticipado no sería sino una aceptación de la garantía como parte del contrato subyacente, es decir, como obligación principal derivada del contrato del que nace en el cual está contenida, pero no constituye consentimiento a la relación de garantía. Esta relación entre garante y beneficiario es independiente del contrato del que nace, con lo que, de ser bilateral, necesitaría un nuevo consentimiento, el cual no llega a producirse, ya que el beneficiario simplemente acude a la entidad financiera a solicitar el pago del importe pactado sin efectuar más actividad que la de aportar los documentos pactados en el contrato subyacente como condición para el ejercicio de su derecho a hacer efectiva la garantía. Así, el cumplimiento de los requisitos para el ejercicio de su derecho por parte del beneficiario no es, como ha afirmado algún sector de la doctrina ${ }^{69}$, una obligación o prestación contractual del beneficiario, sino que resulta ser condición para el ejercicio de un derecho.

Es igualmente significativo para la apreciación de tal carácter de unilateralidad el que, en la relación entre garante y beneficiario, sólo

68 Garrigues, Contratos bancarios, cit. p. 612.

69 Cfr. Garrigues, Contratos bancarios, cit. p. 611. Para AsQuini, Ancora sui pagamenti mediante apertura di credito bancario, «Scritti Giuridici», vol. I, Padua, 1936, pp. 252 y ss., «la entrega de documentos por parte del vendedor será contraprestación causal frente al comprador, pero frente al banco es una simple condición de hecho para el perfeccionamiento de la obligación abstracta del banco de entregar una suma de dinero. 
una parte ostenta derechos, el beneficiario, y sólo a la otra, el banco garante, le corresponden obligaciones, lo que refleja claramente una estructura pura de relación unilateral.

Además, la unilateralidad de la carta de garantía independiente es consecuencia de la necesidad de seguridad jurídica en las relaciones internacionales y de la propia configuración de la garantía cuya existencia y producción de efectos no puede quedar a expensas de la aceptación por su beneficiario, bien fuere ésta expresa, bien pudiera inducirse tácitamente del silencio del beneficiario mantenido durante el breve período prudencial, desde la recepción de la carta de garantía, predicado como inherente a la rapidez o diligencia propia del mundo de los negocios. Es de señalar que el contenido de la garantía habrá sido impuesto por el propio beneficiario a lo largo de las negociaciones del contrato subyacente, el cual contendrá en alguna de sus cláusulas las menciones principales que luego aparecen transcritas en el texto de la garantía. Teniendo en cuenta todo ello, parece más propio considerar que el silencio del beneficiario simplemente será indicativo de su conformidad con el texto de la garantía que le ha sido procurada. Por otra parte, durante tal breve período de tiempo al parecer necesario para entender producido el consentimiento del beneficiario, éste podría exigir al garante el cumplimiento de sus obligaciones de garantía, por lo que no parece coherente la consideración de que un acto jurídico se entienda como no nacido hasta tanto recaiga aceptación del beneficiario, cuando éste puede reclamar al garante la ejecución del contenido del acto jurídico.

La relación que une al garante y al beneficiario de la garantía se concreta en la emisión por el banco garante de la carta de garantía en favor de su beneficiario, momento a partir del cual surge un compromiso firme del garante frente al beneficiario, sobre quien no pende obligación alguna en orden a la reclamación del pago de la garantía, por lo que ${ }^{70}$ cabe plantear la configuración de la carta de garantía bien como contrato unilateral, o bien como negocio jurídico unilateral. Aunque sea objeto de debate ${ }^{71}$, cabe deducir de lo anterior que la situación apuntada es calificable como una declaración unilateral de voluntad constitutiva de un negocio jurídico atípico e innominado, declaración de voluntad en virtud de la cual el banco promitente, dirigiéndose a

70 Cfr. Alonso Ureba, art. cit., pp. 443 y ss. El autor sostiene la calificación del crédito documentario como acto o contrato unilateral.

${ }^{71}$ En sentido contrario se pronuncia CERDÁ Olmedo, op. cit., pp. 41 y ss., afirmando que «...dicho consensus en cuanto a los instrumentos jurídicos utilizados, su extensión y su alcance en cada caso hace que la tesis contractual sea más conforme con la realidad a la hora de explicar la naturaleza de la garantía a primera demanda». 
persona determinada (el beneficiario), se obliga a realizar una prestación (el pago de la cantidad garantizada) cuando le fuere reclamada ${ }^{72}$.

Es, además, un negocio jurídico unilateral no recepticio, pues la promesa unilateral de pago no requiere ser recibida por el vendedor para ser eficaz, quedando vinculado el garante desde su emisión y no desde su recepción o aceptación por el beneficiario. Ello resulta, además, de la propia estructura del negocio, pues la promesa del garante no es realizada en busca de una declaración de aceptación, sino que se orienta a la efectiva realización del comportamiento pretendido, es decir, la reclamación del pago de la suma garantizada. No cabe apreciar, por tanto, la realización de una oferta de contrato, sino una promesa unilateral, sin que haya lugar a plantear la significación del silencio por parte del beneficiario como aceptación de la oferta, y sin que tampoco quepa entender que la aceptación se produce con la reclamación del pago de la garantía. Dicha promesa irrevocable sólo se extinguirá por la reclamación y realización del pago, o por el transcurso del plazo previsto.

\section{C) LA INAPROPIADA CONSIDERACIÓN DE LA GARANTÍA INDEPENDIENTE COMO GARANTÍA DE RESULTADO: EL CARÁCTER INDEMNIZATORIO DE LA GARANTÍA INDEPENDIENTE}

Una parte de la doctrina alemana ${ }^{73}$, siguiendo la tradición jurídica germánica, ha establecido que la garantía independiente, en contraste y a diferencia de una garantía accesoria, cubre un determinado resultado de acuerdo con las previsiones contempladas en la relación jurídica subyacente. Igualmente, los pagos que se produjeran en ejecución de la garantía no guardan relación con los derechos del beneficiario frente al ordenante de la garantía ${ }^{74}$. Las consideraciones de la doctrina alemana encajan con el garantievertrag alemán, pero la garantía de un resultado resulta contradictoria con la independencia de la garantía y parecen poner de manifiesto connotaciones propias de una garantía accesoria.

La garantía independiente no es un procedimiento de ejecución para el supuesto de incumplimiento del deudor principal, pues, aun sin

72 La unilateralidad de las garantías independientes resulta expresamente aceptada por las STS de 14 de noviembre de 1989 en Rep. Jurisp. La Ley, 1989, n. ${ }^{\circ} 7.878$; STS de 15 de abril de 1991, Rep. Jurisp. La Ley 1991, n. ${ }^{\circ}$ 2.693; STS de 27 de octubre de 1992, Rep. Jurisp. La Ley, 1992, n. ${ }^{\circ} 8.584$.

73 Vid. CAEMmerer, art. cit., pp. 295 y ss.; Bertrams, op. cit., p. 44; en el mismo sentido, SÁNCHEZ-CALERO, El contrato autónomo de garantía... cit., pp. 344-346.

74 Bertrams, op. cit., p. 44. 
entrar en la consideración de que el monto de la garantía suele alcanzar un porcentaje menor del total del contrato garantizado, constituye, únicamente, una valoración inicial a tanto alzado de los daños derivados de la defectuosa ejecución del contrato garantizado y significa un pago previo a la determinación judicial, o mediante transacción amistosa, del monto finalmente fijado para tales daños. Por lo tanto, el banco no se compromete a garantizar la ejecución de las obligaciones del contrato, sino a la ejecución de una obligación marginal cual es el pago de la suma convenida. La garantía independiente es, en consecuencia, para la doctrina francesa, algo análogo a un procedimiento de consignación de una suma de dinero, lo que pone de manifiesto una vocación indemnizatoria prefijada en cuanto a su alcance económico ${ }^{75}$.

\section{La calificación jurídica de la figura de las garantías independientes}

Entre los rasgos que caracterizan a la garantía independiente se encuentra su calidad de garantía personal singularizada por su autonomía e independencia respecto del contrato subyacente de la que se deriva la inoponibilidad frente al beneficiario de aquellas excepciones que pudieran derivarse de dicho contrato. Existe, pues, por hipótesis, un contrato subyacente sin el cual la idea misma de garantía no tendría sentido. Sin embargo, una vez constituida dicha garantía, el nexo con el contrato subyacente queda oculto, aunque no desaparecido, por lo que su calificación como acto materialmente abstracto debe ser descartada ${ }^{76}$.

\section{A) LAS GARANTÍAS INDEPENDIENTES COMO CONTRATO «SUI GENERIS»}

Los ordenamientos jurídicos, confrontados con la cuestión de la calificación a dispensar a las garantías independientes, concluyen la dificultad de la reconducción de la figura a ninguno de los tipos conocidos de manera adecuada, por lo que optan por la consideración de las garantías independientes como contrato sui generis.

Tal calificación es la que pareció sugerir Lord DenNING tras concluir que las garantías eran a new creature que se basaban en los mismos principios en que lo hacían los créditos documentarios, afirmando

75 Cabrillac y Mouly, Le droit des suretes, cit. p. 353, donde los autores afirman: «La garantie indépendante remplace un depot de garantie; la garantie indépendante n'a pas pour objet l'exécution du contrat principal mais la consignation d'un depot de garantie».

76 SiMLER, op. cit., p. 683. 
en cuanto a la calificación jurídica de las mismas que... these performance guarantees are virtually promissory notes payable on demand ${ }^{77}$.

En el seno de los ordenamientos de inspiración germánica, la doctrina alemana ${ }^{78}$ acepta la tesis de CANARIS ${ }^{79}$ según la cual no cabe apreciar grado alguno de analogía entre la asignación y las garantías independientes. Por ello, la doctrina alemana se conforma con la apreciación de la naturaleza abstracta sui generis de las garantías independientes a primera demanda.

En relación al derecho suizo, se afirma la imposibilidad de asimilación de las garantías independientes a la figura de la asignación del art. 468 del Code des Obligations, mediante la cual el asignante hace ejecutar su propia obligación por el asignado, quien actúa en su propio nombre pero por cuenta de un tercero, lo que efectivamente resulta posible en el supuesto de los créditos documentarios pero no puede producirse en el caso de las garantías independientes. Asimismo se afirma la imposibilidad de su asimilación al contrato de porte-fort regulado en el artículo 111 del Code des Obligations. Por todo ello, considera la doctrina $^{80}$ que las características esenciales de las garantías independientes no aparecen recogidas en ninguno de los contratos que disponen de un nomen iuris por lo que se trata de un tipo innominado sui generis.

La doctrina italiana ${ }^{81}$, por su parte, acepta la existencia de un contrato de garanzia pura que se corresponde con una función económica y social digna de protección cuya admisibilidad se deriva del principio de autonomía contractual, siendo la identificación de su causa la cuestión de mayor relevancia al objeto de la definitiva admisión de la figura, aun cuando algunos autores entienden que permanece abierta la cuestión de la validez de tal nuevo tipo de garantía personal.

Por lo que se refiere a la doctrina y jurisprudencia francesas ${ }^{82}$, no parecen mostrar gran preocupación por la reconducción de la figura a determinado tipo jurídico. La utilización del término garantía va seguido del énfasis en la independencia y abstracción de la figura. A se-

77 Lord DenNing dedujo del examen de las obligaciones del garante que «la garantía de ejecución tiene un régimen similar a las cartas de crédito» y también afirmó: «estas garantías de ejecución son virtualmente títulos a la orden pagaderos a la vista», Edward Owen Engineering Ltd. vs. Barclays Bank International Ltd. en apelación (1977), 3, WLR, 734; Lord Denning afirmó en 1977 «A performance bond is a new creature so as far as we are concerned».

78 Cfr. CAEMmerer, Bankgarantien..., cit. p. 305.

79 CANARIS, Banvertragsrecht, cit. p. 592.

80 DoHM, op. cit., p. 66.

81 Vid. especialmente MAZzoni, art. cit., p. 292; BenATtI, art. cit., p. 181.

82 Cfr. Cabrillac y Mouly, op. cit., p. 354. 
mejanza de la orientación seguida por el sistema jurídico italiano y tratándose de un orden profundamente causalista, la apreciación de la existencia de una causa de la garantía y su identificación parece ser cuestión de mayor relevancia.

En el derecho español, aceptando la voluntad unilateral como fuente posible de obligaciones, es posible configurar la carta de garantía como contrato unilateral o como negocio jurídico unilateral ${ }^{83}$, declaración de voluntad constitutiva de un negocio jurídico atípico, innominado y no recepticio ${ }^{84}$, que contiene una promesa de pago unilateral.

\section{B) LAS GARANTÍAS INDEPENDIENTES EN LA JURISPRUDENCIA DE LOS TRIBUNALES ESPAÑOLES Y SU CONFIGURACIÓN COMO PROMESA UNILATERAL DE PAGO}

El TS parece tomar como punto de partida el carácter imperativo que reviste la regulación legal de los caracteres esenciales de la fianza ${ }^{85}$, de forma que, derogados o alterados éstos por la voluntad de las partes, habrá nacido una figura dotada de plena validez jurídica, pero no reconducible al tipo contractual de la fianza. Para el TS, una garantía no accesoria no es una fianza. En otros términos, las normas de la fianza relativas a su accesoriedad son típicamente imperativas de forma que, cuando el supuesto de hecho sea reconducible al tipo de la fianza, tales normas resultarán inexcusablemente de aplicación ${ }^{86}$.

83 Garrigues, Curso de derecho mercantil, 7. a edición, Madrid, 1980, p. 11

${ }^{84} \mathrm{Cfr}$. al respecto la exposición de AlONSO UREBA, art. cit., pp. 460 y sigs.

${ }^{85}$ Los pronunciamientos del TS pueden ser agrupados: $\left.1 .^{\circ}\right)$ tras las STS antes citadas (cfr. supra notas 8 y 9) de 2 de octubre de 1990 y 15 de abril de 1991, en principio opuestas a la aceptación de la figura de las garantías independientes, cabe hacer mención de aquellas sentencias preparatorias de la aceptación de las garantías independientes, cuales son la STS de 21 de marzo de 1980 (Rep. Aranzadi, 1980, n. ${ }^{\circ}$ 1.132) que se refirió a un aval en sentido amplio que no definió, y la STS de 11 de julio de 1983 (Rep. Aranzadi, 1983, n. ${ }^{\circ}$ 4.209) la cual menciona como obiter dictum la necesidad de aceptar nuevas figuras de garantía personal para superar la rigidez de la fianza. . $^{\circ}$ ) En segundo lugar, se pueden agrupar los pronunciamientos en los que, de forma central, el TS ha elaborado lo substancial de su doctrina al respecto, y que resultan ser: la STS de 14 de noviembre de 1989 (Rep. Aranzadi, 1989, n. ${ }^{\circ} 7.878$, la STS de 8 de mayo de 1991 (Rep. La Ley, 1993, n. ${ }^{\circ} 11.780$ y, muy en particular, la STS de 27 de octubre de 1992 (Rep. La Ley, 1993, n. ${ }^{\circ} 13.168 .3^{\circ}$ ) Por último, cabe hacer mención de los posteriores pronunciamientos que vienen a confirmar la doctrina sentada en las sentencias anteriormente mencionadas: STS de 3 de mayo de 1999, en Actualidad Civil, 1999, n. ${ }^{\circ}$ 30, St. n. ${ }^{\circ}$ 749; STS de 10 de noviembre de 1999, en Actualidad Civil, 2000, n. ${ }^{\circ} 9$, St. n. ${ }^{\circ}$ 178; STS de 17 de febrero de 2000, en Actualidad Civil, 2000, n. ${ }^{\circ}$ 24, St. n. ${ }^{\circ}$ 537; STS de 30 de marzo de 2000, en Actualidad Civil, 2000, n. ${ }^{\circ} 32$, St. n. ${ }^{\circ} 729$; STS de 5 de julio de 2000, en Actualidad Civil, 2000, n. ${ }^{\circ} 44$, St. n. ${ }^{\circ} 1.078$.

86 STS de 27 de octubre de 1992, Fundamento de Derecho segundo; cfr. supra nota 89. 
«...la obligación de pago asumida por el garante se constituye como una obligación distinta, autónoma e independiente, de las que nacen del contrato cuyo cumplimiento se garantiza. Es nota característica de esta forma de garantía personal, que la diferencia de la fianza regulada en el Código civil, su no accesoriedad...».

El TS ya había puesto de manifiesto que las necesidades del tráfico mercantil internacional no quedaban adecuadamente servidas mediante la figura de la fianza. Así lo había hecho en la STS de 11 de julio de $1983^{87}$ en la que, refiriéndose a un «aval en sentido amplio» que no definió, había afirmado:

«...como instrumentos complementarios de las garantías reales...se viene planteando en el ámbito jurídico la problemática de las garantías personales...frente a una visión tradicional que pudiera reconducir las garantías personales a las obligaciones cambiarias o a la fianza, han aparecido nuevas figuras que tendiendo a superar la rigidez de la accesoriedad, es decir, la absoluta dependencia de la obligación garantizada para la existencia y la misma supervivencia, como lo revelan sobre todo... las garantías denominadas de primera solicitud en el comercio internacional...».

Por lo que a nuestro sistema jurídico se refiere, la doctrina del TS permite, por recurso al principio de libertad contractual, la creación de nuevas figuras contractuales y, de forma más específica, reconoce la validez de la garantía independiente y su diferenciación del tipo de la fianza. Apoyándose en el principio de libertad de pacto del artículo $1.255 \mathrm{CC}$, afirma la STS, anteriormente comentada, de 14 de noviembre de 1989:

«...es llano que no nos encontramos ante una fianza, sino ante otro tipo de garantía exigible en las condiciones pactadas, y toda interpretación que trate de dar a la palabra garantía el sentido de la obligación accesoria de fianza o de aplicar la excusión que le es característica desvirtúa la naturaleza de la relación jurídica compleja a la venimos haciendo mérito, para lo que no existe obstáculo legal en orden a su eficacia en nuestro ordenamiento positivo, que encuentra su fuerza vinculante en el principio de libertad de contratación proclamado en el artículo 1.255 CC...».

87 Con anterioridad, el TS, en su sentencia de 21 de marzo de 1980 (cfr. supra nota 89) se había referido a un aval en sentido amplio, aval solidario de una serie de letras cambiarias. El TS estableció que existe un concepto más amplio de aval en cuanto contrato de garantía de cumplimiento de otros negocios y por virtud del cual una o varias personas se comprometen a cumplir una obligación ya existente o que se crea en ese momento otorgándole carácter solidario. Vid. comentario de BlANCO CAMPAÑA, Aval cambiario y aval como contrato de garantía, cit. pp. 167-182. 
El TS se ha pronunciado de forma específica en sus sentencias de 14 de noviembre de $1989^{88}, 8$ de mayo de $1991^{89}$ y 27 de octubre de $1992^{90}$.

En la primera de ellas, el tribunal acude a la figura de la promesa de pago unilateral e irrevocable ${ }^{91}$. Para ello basa su argumentación: $1^{\circ}{ }^{\circ}$ ) en el artículo $1.255 \mathrm{CC}$ y $2 .^{\circ}$ ) en el paralelismo de la figura del crédito documentario respecto de un supuesto de carta de garantía emitida por una Compañía de seguros en virtud de la cual dicha compañía por cuenta de su cliente se comprometía frente a un tercero a pagarle de inmediato contra la presentación de una simple petición por escrito. El TS afirma que la garantía contemplada en el supuesto objeto de la litis «se parece a lo que, con nombre ciertamente equívoco, se viene denominando apertura de crédito documentario contemplado por las reglas y usos uniformes fijados por la Cámara de Comercio Internacional».

En la segunda sentencia, de 8 de mayo de 1991, se reitera esta doctrina jurisprudencial, al apreciar el TS que la intervención del banco se

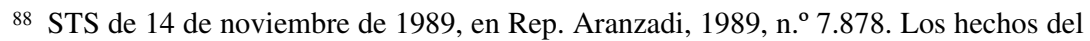
caso eran los siguientes: la sociedad «Lubricantes del Sur, S.A.» (Lubrisur) había contratado con «Stein et Roubaix Española, S.A.» el suministro, montaje y puesta a punto de un generador de vapor. Por su parte, Stein suscribió con Crédito y Caución, S.A., una póliza de seguro en garantía de la ejecución del contrato de obra con suministro. Por ello, Crédito y Caución dirigió a Lubrisur la correspondiente carta de garantía. Posteriormente, Lubrisur se dirigió a Crédito y Caución reclamándole el pago inmediato de la cantidad garantizada, por entender que Stein había incumplido el contrato, negándose la Compañía de Seguros garante al pago porque de los informes que había obtenido no resultaba un incumplimiento del contrato por parte de Stein.

89 TS de 8 de mayo de 1991, Rep. La Ley, 1991, n. ${ }^{\circ} 11.780$. Los elementos de hecho eran como sigue: se trataba de una compraventa de tecnología entre un comprador español y la sociedad «Ampex World Operations, S.A.». El comprador había procedido a la compra para, posteriormente, revender lo comprado a Televisión Española de acuerdo con los términos de un contrato administrativo existente entre ambos. Como intermediario participó el entonces Banco de Vizcaya, con ulterior intervención como fiador, pero sin asunción definitiva del débito. La mercancía llegó en debidas condiciones a RTVE, quien la aceptó, pero se demoró en el pago y, por ello, el comprador intermediario no pudo realizar su correspondiente pago al no poder entregar, tal como había comprometido, las letras aceptadas y avaladas por un banco.

90 STS de 27 de octubre de 1992, Rep. La Ley, 1993, n. ${ }^{\circ}$ 13.168. La STS se refería a un aval solidario prestado por Banca Catalana a favor de «Cementos La Robla» para garantizar a ésta el cumplimiento por «Unitherm Española» de las obligaciones derivadas de un contrato de suministro de equipos, maquinaria e instalaciones, con renuncia a los beneficios de excusión y división y calificado como aval o garantía a primera solicitud. El TS dispensa en su sentencia respaldo a la calificación dada al aval por el Juzgado, y aprovecha la ocasión para hacer una síntesis de la doctrina jurisprudencial más favorable a la recepción y reconocimiento de la garantía independiente. Cfr. Coca y FlaQUER, art. cit., pp. 473-483.

91 Alonso Ureba, art. cit., pp. 443 y ss. 
asemejaba a la posición que un banco ocupa en el crédito documentario en cuanto emisor del mismo para, a continuación, volver a utilizar la calificación de promesa abstracta de pago:

«la "remesa documentaria", no consistió, como dice el recurso, en delegación de deuda sino en una relación análoga al crédito documentario... ...en cuya relación de pago el banco denominado emisor no toma parte directa en la relación sustantiva civil subyacente que pretende liquidar...».

Por su parte, la STS de 27 de octubre de 1992 se refería a un aval a primer requerimiento para garantizar el cumplimiento de las obligaciones derivadas del contrato base. La claridad de los términos en que estaba redactado el contrato de garantía («garantizamos a Vds. hasta el límite...»;《el presente documento tiene carácter solidario...»; «renunciamos expresamente a los beneficios de orden, excusión y división...»; «el aval se hará efectivo a Vds. a su primer aviso...») y la negativa del banco a ejecutar la misma produjo la interposición de la demanda. El TS apreció la responsabilidad de la institución financiera y afirmó:

«...entre las nuevas modalidades de garantías personales nacidas para satisfacer las necesidades del tráfico mercantil al resultar insuficiente o inadecuada la regulación legal de la fianza, se encuentra el aval a primera solicitud, o a primer requerimiento, también denominado por la doctrina como garantía a primera demanda o a simple demanda o garantía independiente, contrato atípico, producto de la autonomía de la voluntad sancionada por el art. 1255 CC...».

La St. reproduce la doctrina contenida en la STS de 11 de julio de 1983, así como, de manera textual, la doctrina contenida en la antes citada STS de 14 de noviembre de 1989 en aplicación de tal doctrina al aval a primer requerimiento, con lo que viene a establecer el patente paralelismo entre ambas figuras. Es de destacar la expresa caracterización del contrato de garantía como aval a primer requerimiento o garantía a primera demanda, así como su no accesoriedad y abstracción ${ }^{92}$.

Junto a las citadas Sts. del Tribunal Supremo ${ }^{93}$, por su especial claridad merece hacerse mención de la St. de la AP de Palencia, de 5

92 Vid. comentarios de DíAz MoReno, en Las garantías a primer requerimiento en la jurisprudencia del Tribunal Supremo, cit. pp. 629-632; SÁnCHEZ-CALERo GuILARTE, El reconocimiento jurisprudencial... cit. pp. 3.057-3.075; BARRÉS BENLLOCH, El aval bancario como garantía autónoma, en La Ley, 1993-3, pp. 314-319.

93 Entre los pronunciamientos de las Audiencias Provinciales, corresponde hacer mención de la St. de la AP de Pontevedra, de 22 de marzo de 1995 (Actualidad Civil, Audien- 


\section{de febrero de $1996^{94}$, cuyos dos primeros Fundamentos de derecho es- tablecen:}

«El recurrente trata de reconducir el contrato...a la fianza en garantía de deuda futura contemplada en el artículo 1825 CC...mas olvida que se expresa que la entidad bancaria queda autorizada a la entrega de las sumas que les sean requeridas hasta el importe de la garantía prestada, al primer requerimiento que reciba para ello, sin necesidad de la previa conformidad del afianzado y, por tanto, sin que la Caja tenga que entrar a considerar respecto de la procedencia o no de la petición de reintegro. Por tanto la consideración del pacto revela que...nos hallamos ante una garantía a primera demanda o a primera solicitud...modalidad de garantía personal que constituye un contrato atípico, nacido de la autonomía de la voluntad consagrada en el artículo $1255 \mathrm{CC}$, precisamente para dar respuesta a las necesidades del moderno tráfico mercantil al que en ocasiones resulta insuficiente la fianza.

Dicho atípico contrato es admitido por la jurisprudencia, que le otorga carta de naturaleza en ya repetidas sentencias (cual la de 27 de octubre de 1992,y la de 14 de noviembre de 1989 a que aquella se remite), caracterizándola precisamente, a diferencia de la fianza, por su no accesoriedad, por su independencia respecto a la obligación garantizada, de modo que la entidad bancaria promete el cumplimiento de una obligación autónoma y propia cuya exigibilidad se desencadena por el requerimiento del beneficiario, sin necesidad de prueba o justificación alguna

cias, $n^{\circ}{ }^{\circ} 16 / 16$, pp. 1.340-1.341) acerca de la «entrada en vigor» de una garantía a primera demanda; el problema planteado estribaba en la extensión de la garantía, dado que se había suscrito en una fecha posterior al inicio de las operaciones que debía cubrir; el tribunal establece que ello no contraría la noción de independencia de toda garantía a primer requerimiento. El argumento seguido por la AP para la extensión de la garantía a las operaciones de suministro realizadas con anterioridad a su suscripción se basa en que, de modo similar, las obligaciones de pago de los suministros se habían instrumentado en diversas cambiales no creadas al tiempo de emisión de las facturas o suministros. Resulta igualmente de interés la sentencia de la AP de Madrid, de 15 de septiembre de 1997 (Rep. La Ley, 1998, pp. 1.145), cuyo objeto es la existencia o no de un aval a primer requerimiento; el tribunal, confirmando la sentencia de primera instancia, establece que no se trataba de un contrato de seguro, sino del mencionado aval, todo ello deducido de ciertas expresiones del contrato de garantía suscrito y de la no aportación por la compañía demandada (entidad garante) de la póliza de seguro. La sentencia de la AP de Madrid, de 30 de enero de 1995 (BD. El Derecho, n. ${ }^{\circ} 11.016$ ), como obiter dictum, define el aval a primera solicitud y declara sus características, con apoyo en las STS de 11 de julio de 1985 y de 14 de noviembre de 1989. Otras Sentencias de diversas Audiencias, tales como la St. AP. de Asturias, de 15 de diciembre de 1998 (BD. Aranzadi, AC 1998/2412), la St. de Alicante, de 3 de diciembre de 1999 (BD. Aranzadi AC 1999/2461), la St. AP de Guipúzcoa, de 9 de diciembre de 1999 (BD. Aranzadi AC 1999/2590), la St. AP de Alicante, de 16 de diciembre de 1999 (BD Aranzadi AC 1999/2463) siguen las pautas analizadas y respaldadas por el TS.

94 St. AP de Palencia, de 5 de febrero de 1996, en Actualidad Civil, abril, 1996, pp. 509-511. 
del efectivo incumplimiento del contrato o contratos garantizadas, todo ello sin perjuicio de las acciones que luego puedan derivarse del pago de la garantía y de su regreso frente al afianzado entre éste y el beneficiario».

\section{El régimen jurídico de las garantías independientes: las condiciones para su validez}

El contrato de garantía independiente está únicamente regulado por las disposiciones de la carta de garantía al no existir normativa reguladora de este tipo de garantías o que pudiera aplicarse por analogía ${ }^{95}$.

La carta de garantía suele tener un tenor escueto. En la práctica, las garantías independientes pueden ser emitidas mediante un intercambio de telex o de faxes, y cuando se requiere carta de confirmación, ésta suele ser una reproducción del texto comunicado por telex o por fax. A pesar de ello, el texto de la garantía es la única forma de establecer las obligaciones asumidas por las partes. Por otra parte, la garantía independiente es un contrato en cuanto tal sometido a las reglas generales de validez de los contratos ${ }^{96}$, por lo que debe reunir las condiciones para la validez de los contratos: capacidad, consentimiento, causa y objeto, además de la cuestión de la forma.

\section{La forma de la garantía}

Los garantes profesionales persiguen la observación de los comportamientos acuñados por la práctica en materia de crédito documentario, de acuerdo con los cuales el banco verifica únicamente documentos y no la cantidad y calidad de las mercancías. Tal pretensión de trato exclusivo sobre documentos y la inexistencia de un deber de inmiscuirse en la ejecución del contrato principal son perfectamente legítimas, pues los bancos no tienen ni la competencia, ni el tiempo u oportunidad, ni la misión de erigirse en jueces o árbitros de la ejecución del contrato.

95 Afirmación del Trib. de Casation francés, de 20 de diciembre de 1982, que confirmó la admisión de las garantías independientes en el sistema francés, comentada por VASSEUR, en Rev. Trimestrielle de Droit Commercial, 1983, p. 446.

96 Vid. Gavalda y Stoufflet, La carte de garantie... cit. n. ${ }^{\circ}$ 6; Mazzoni, Les garanties bancaires en droit italien, cit. pp. 282-284. 
En aplicación de dicha idea, los tribunales declaran constantemente que la garantía se rige exclusivamente por los términos contenidos en la carta de garantía, lo que no significa el nacimiento de un nuevo formalismo, sino la expresión de dicha ausencia de verificación por el garante acerca de la inejecución del contrato principal. No cabe extraer de ello otras consecuencias, pues el régimen de la garantía independiente queda igualmente conformado por otras normas y criterios no contenidos en el texto de la garantía, particularmente en lo relativo a su extinción. Igualmente, la propia calificación de la obligación como fianza o como garantía independiente descansa en la apreciación de elementos complementarios al texto del contrato, sobre todo los usos de la profesión bancaria o el contexto interno o internacional del contrato ${ }^{97}$. La única forma de entender limitado el régimen de la garantía al texto de la propia carta de garantía consistiría en que el derecho del acreedor estuviera incorporado al título, como si se tratara de un título al portador, lo que no es el caso puesto que, en principio, queda descartada la transferibilidad de la garantía ${ }^{98}$.

El principio general relativo a la forma de las garantías independientes reza que, al ser las garantías fruto de la libertad contractual, no están sometidas a especiales requisitos de índole formal, sino que, por el contrario, el principio general al respecto es el de plena libertad formal. Al ser generalmente emitidas por instituciones financieras, siempre constan por escrito. La tendencia de las reglamentaciones internacionales se orienta hacia la exigencia de la constancia de la carta de garantía, aunque aceptando que dicha constancia no se produzca necesariamente en forma escrita, pues puede ser suficiente un soporte informático ${ }^{99}$.

97 Cfr. Cabrilac y Mouly, Droit des suretes cit., p. 335; Mattout, op. cit., p. 156.

98 La transferibilidad de la garantía es cuestión discutida. Siendo intransferible a menos que el texto de la carta de garantía contemple expresamente dicha transferibilidad, está fuertemente impregnada de un carácter intuitu personae. Tal es el pronunciamiento del artículo 4 RUGD: »El derecho del beneficiario a presentar una demanda con base en una garantía no es transferible, a menos que esté expresamente estipulado en la garantía o en una enmienda de la misma»; al respecto vid. MatTout, op. cit., p. 157.

99 Criterio básicamente introducido por la Convención de las Naciones Unidas, artículo 7.(2): «an undertaking may be issued in any form which preserves a complete record of the text of the undertaking an provides authentication of its source by generally accepted means or by a procedure agreed upon by the guarator/issuer and the beneficiary». Por su parte, las RUGD imponen su constancia por escrito, y determinan el contenido mínimo de las mismas. Artículo 2d, Publicación CCI n. ${ }^{\circ} 458,1992$ : «las expresiones "escrita" y "por escrito" incluyen las teletransmisiones autentificadas o mensajes controlados de intercambio de datos informáticos (EDI) equivalentes». 


\section{La capacidad de las partes}

El carácter independiente del compromiso no puede tener incidencia sobre la aplicación de las reglas relativas a la capacidad. Las reglas reguladoras de la fianza que no fueren consecuencia de su carácter accesorio, pueden, pues, ser traspuestas.

Ha lugar a precisar que las garantías independientes emitidas por personas jurídicas deben obedecer las reglas generales en materia de derecho societario ${ }^{100}$. De nuevo, la analogía con las reglas relativas a la fianza resultan de aplicación, puesto que es la calificación de garantía personal lo que las justifica, y no su carácter accesorio o autónomo. De esta forma, la conformidad con el objeto social debe ser respetada. Ocurre igual con las reglas específicas de las sociedades anónimas, o las relativas a instituciones bancarias o financieras.

\section{El consentimiento}

El contrato de garantía requiere un acuerdo de voluntades que conste de forma explícita, pues no puede concebirse que, sin una formulación precisa y generalmente escrita, se pueda reconocer y aceptar el carácter independiente de la obligación de garantía. El consentimiento del beneficiario no resulta necesario si se acepta que la garantía es un acto unilateral y no recepticio. En una concepción bilateral de la misma, cabrá entender que la aceptación puede ser tácita ${ }^{101}$ y ser el resultado que se desprende de la actuación de las partes; así, por ejemplo, en cuanto a las relaciones entre el ordenante y el banco contragarante, se puede deducir el consentimiento por la emisión de la contragarantía; en las relaciones entre banco contragarante y el banco que proporciona la garantía en primer grado, por la propia emisión esta garantía; o en cuanto a las relaciones entre el banco garante de primer grado y el beneficiario, el consentimiento se puede deducir de la apreciación de un comportamiento que implique la aceptación (pago de anticipos, firma del contrato...).

La noción de vicios del consentimiento es igualmente aplicable a las garantías independientes ${ }^{102}$. Al ser emitidas principalmente por ins-

100 Vid. al respecto SÁNCHEZ CALERo, art. cit., p. 55.

101 Para Gavalda y STOUfFLet la aceptación resulta del silencio observado durante un plazo razonable y apropiado a la vida de los negocios tras la recepción de la notificación de la garantía, La lettre de garantie internationale, cit., n. ${ }^{\circ} 13$.

102 Vid. SÁnCHEZ CALERO, art. cit., p. 54; SIMLER, Le cautionnement... cit., p. 713. 
tituciones financieras, la cuestión tendrá pocas posibilidades de convertirse en litigiosa. El error, el dolo, o la violencia, podrían viciar el consentimiento del garante. Al tratarse de un contrato que contiene, como único compromiso, el pago de una cantidad de dinero, la posibilidad de error sólo se dará en circunstancias excepcionales. En cuanto al dolo, se toma en consideración cuando emana del beneficiario de la garantía (o del garante en primer grado, en el caso de la contragarantía) lo que reduce sensiblemente las posibilidades de anulación de la garantía por esta causa.

La independencia de la garantía y de la contragarantía impiden al garante obtener provecho de un vicio de consentimiento que afecte de nulidad al contrato subyacente o a algún otro eslabón de la cadena de garantías.

\section{La causa de la garantía independiente}

La problemática relativa a la causa de la garantía independiente ha sido objeto de debate doctrinal impulsado por la necesidad de fundamentación de la abstracción consubstancial a la independencia de las garantías. Al tratarse de un contrato unilateral del que se deriva la obligación de pagar una suma de dinero, parece de ello derivarse que la causa de tal obligación tendrá que ser necesariamente buscada fuera del propio contrato. No parece quepa sostener que la causa de la obligación del garante es la garantía otorgada a favor del beneficiario, pues ello sería confundir causa y objeto.

\section{A) La CAUSA DEL CONTRATO}

Nuestro sistema jurídico es causalista ${ }^{103}$, de forma que todo acto jurídico debe tener una causa de la que se derive su validez jurídica. Expone De CASTRO ${ }^{104}$, que la función que nuestro derecho atribuye a la causa radica en la valoración de cada negocio, hecha atendiendo al resultado que con él se busca o se hayan propuesto quien o quienes hagan la o las declaraciones negociales. Por su parte, DíEz PICAZO ${ }^{105}$, señala

103 Díez Picazo, Fundamentos... cit. pp. 157-181; Gullón Ballesteros, Curso de derecho civil, cit., pp. 55-89, en especial, la explicación acerca de la evolución histórica de la noción de causa; CASTÁn, Derecho civil español, cit. pp. 533-543; Clavería Gosálvez, Comentarios a los artículos 1.274, 1.275, 1.276 y 1.277 del Código Civil en «Comentarios al Código Civil y Compilaciones Forales», dir. Albaladejo, tomo XVII, vol. 1-B, Edersa, Madrid, 1993, pp. 519 y ss.

104 De CASTRO, El negocio jurídico, Madrid, Civitas, 1985, p. 188.

105 Díez Picazo, Fundamentos, cit., pp. 171-175. 
que causa de la obligación y causa del contrato constituyen conceptos diferenciados que con frecuencia aparecen entremezclados, como un fruto de la confusión entre contractus y obligatio contracta: $\left.1 .^{\mathrm{a}}\right) \mathrm{La}$ primera (causa de la obligación, causa debendi) se refiere a la razón que fundamenta jurídicamente la existencia de una deuda, el hecho constitutivo de la obligación, la fuente de la obligación, un supuesto de hecho al cual el ordenamiento jurídico liga la obligación. 2.a ) La segunda (causa contractus, causa negotii) hace alusión a la razón que llevó a la celebración del negocio, aun cuando en relación a ella se produzcan opiniones doctrinales encontradas, según se la identifique con la causa determinante o eficiente del negocio o con la razón de que reciba, por parte del ordenamiento jurídico, protección como tal negocio. Un negocio jurídico es protegido porque es un cauce idóneo para alcanzar una serie de finalidades prácticas, empíricas, que son serias y merecen la tutela del ordenamiento. La causa, sin embargo y en rigor, es la causa eficiente o determinante de que un negocio se realice.

En la doctrina mercantilista puede apreciarse una línea de pensamiento básicamente desarrollada a propósito de la letra de cambio o de los títulos-valores ${ }^{106}$, que viene a fundamentarse, a semejanza de la distinción realizada por la doctrina civilista entre negocios originales y negocios de ejecución, en la consideración unitaria y conjunta, tanto de la letra de cambio o título valor como de los actos que a los mismos preceden y que constituyen su presupuesto jurídico y económico al efecto de apreciación de la causa. Cuando los mercantilistas hablan de la causa de la cambial, expone LANGLE ${ }^{107}$, no aluden a que la promesa de pago que contiene, hecha por una parte, tenga su contraprestación por la otra parte, sino que se refieren al contrato fundamental u originario, que se señala y considera como pacto precedente a la emisión de la letra. Prosigue el citado autor afirmando que «la relación fundamental da causa a la letra de cambio, pero no es la causa de ella; la causa está, por el contrario, en el hecho de crear y adoptar la cambial con el fin de establecer (o reforzar) un débito no cambiario, o sea, la prestación que es debida por la relación fundamental (función instrumental de la expedición de la letra)».

La doctrina mercantilista, según expone GARRIGUES ${ }^{108}$, ha transportado al terreno de los títulos-valores la terminología de «negocios cau-

106 PAZ-AREs, Naturaleza jurídica de la letra de cambio, en «Derecho cambiario: Estudios sobre la ley cambiaria y del cheque», Civitas, Madrid, 1986, págs. 95-250; GARRIGUES, Tratado de Derecho mercantil, cit. pp. 191-207.

107 Cfr. Langle, Curso de derecho mercantil, cit. pp.71 y ss.

108 Garrigues, Tratado de Derecho mercantil, cit. p. 37. 
sales» $\mathrm{y}$ «negocios abstractos», pero otorgando al término causa un significado diverso del de causa de la atribución patrimonial. No se trata de la causa de las obligaciones incorporadas al título, respecto de las cuales subsiste el concepto civilista de causa como justificación de la transmisión patrimonial, sino de la causa del título mismo como negocio jurídico, es decir, el presupuesto jurídico-económico de la creación y entrega del título, y tal presupuesto será la relación jurídica que explica y justifica esa creación y esa entrega al acreedor. Tales precedentes contratos son, en último término, la razón de ser de la letra, por lo que se dice que constituyen su causa, entendiendo ello no en el sentido civilista de causa de la obligación, sino en el sentido mercantilista de causa de creación del título cambiario como negocio jurídico, es decir, en el sentido de causa de su creación y entrega o causa de su transmisión una vez creado. Sobre tal concepto de causa, la doctrina mercantilista establece la contraposición entre títulos causales y títulos abstractos, fundamentándola no en el sentido de que haya títulos que tienen causa y otros que carecen de ella, sino en el sentido de que los primeros, los causales, funcionan ligados al negocio causante, mientras que los segundos o abstractos funcionan desligados de ese otro negocio. La ley rompe respecto de estos últimos el nexo entre el título y la causa, configurando de modo autónomo las obligaciones incorporadas al documento ${ }^{109}$.

En similar línea de pensamiento, afirma PAZ ARES ${ }^{110}$, que el negocio cambiario se apoya en el negocio causal subyacente. Mientras que en relación a la convención ejecutiva «...la causa (de la atribución) no es exactamente la relación fundamental, - por ejemplo, un contrato de compraventa-, sino el acuerdo de emitir y entregar una letra de cambio para pagar dicha compraventa». Por lo tanto, para dicho autor, «la causa del negocio cambiario ha de localizarse en lo que viene llamándose pactum de cambiando, que hoy se denomina convenio o convención ejecutiva. Este convenio (expreso o tácito, autónomo o unido al clausulado del contrato fundamental) puede definirse como aquel acuerdo por el cual deudor y acreedor convienen dar y tomar una letra para ejecutar o garantizar y en su caso modificar una determinada relación causal».

\section{B) LA DISTINCIÓN ENTRE NEGOCIOS INICIALES Y NEGOCIOS EJECUTIVOS}

Hay negocios que tienen su causa en otros negocios anteriores y negocios que tienen su causa en sí mismos, escribe DíEz PiCAzo. Esta

109 Ibidem, p. 196.

110 PAz ARES, Naturaleza jurídica de la letra de cambio, cit. p. 209. 
distinción conduce al reconocimiento de los negocios ejecutivos que presuponen un negocio o una situación anterior o antecedente, y que se realizan para desarrollar, cumplir o ejecutar un negocio anterior, considerados así como contrapuestos a los negocios iniciales que dan comienzo a la relación entre las partes ${ }^{111}$.

Existe así una acepción de la abstracción que sólo encuentra aplicación en los denominados negocios ejecutivos, que son aquellos que por limitarse a garantizar, modificar o de cualquier otra forma concretar una relación jurídica preexistente, precisan en todo caso de lo que suele denominarse «negocio subyacente», entre los que se encuentran por ejemplo la fianza, la hipoteca, la letra de cambio, la transacción, el reconocimiento y la promesa de deuda o el crédito documentario. En un plano estrictamente económico no puede caber duda de que todo negocio ejecutivo se halla siempre y en toda circunstancia vinculado a su negocio principal; sin embargo, con alguna frecuencia se plantea la conveniencia de independizar jurídicamente negocio subyacente y negocio ejecutivo para lograr que las excepciones dimanantes del negocio principal no puedan ser esgrimidas en el marco del negocio ejecutivo. La finalidad de esta ruptura puede radicar bien en facilitar la cesión a terceros del crédito incorporado al negocio ejecutivo, o bien en aumentar la seguridad que tal negocio proporcione. Cuando se produce esta independencia entre negocio ejecutivo y negocio subyacente, es frecuente hablar del carácter abstracto del negocio ejecutivo. De acuerdo con esta concepción, el término «abstracto» no se halla intrínsecamente vinculado al concepto de causa, puesto que un negocio puede ser abstracto en este sentido sin que sea preciso que su eficacia sea independiente de su causa, sino que exista una total independencia entre el propio negocio y el que le subyace. A esta concepción de la abstracción se le denomina abstracción funcional, para distinguirla de la procesal y de la material. Parece claro, apunta DíEz PICAZO ${ }^{112}$, que la causa de los negocios ejecutivos es esta situación básica y subyacente que les sirve de antecedente y soporte, cuya inexistencia se traduciría en la ineficacia del negocio y enlaza con la idea de los negocios abstractos, en cuanto negocios ejecutivos desligados del negocio antecedente, mientras que la causa de los negocios iniciales radicará en el propósito práctico o empírico que a través del negocio se trata de obtener.

En consecuencia, cuando se menciona el carácter abstracto de la garantía independiente, tal calificación significa que el contrato que une a garante y beneficiario es independiente tanto del contrato subya-

111 Vid. Díez Picazo, Fundamentos, cit., pp. 174-175 y Alonso Ureba, art. cit., p. 443.

112 Cfr. Díez Picazo, Fundamentos, cit., p. 174. 
cente como del de comisión, por lo que el término abstracto se está utilizando en su acepción funcional, ya que con él se quiere resaltar la inoponibilidad frente al banco de las excepciones que podrán derivarse de la relación subyacente.

\section{C) La CAUSA DE LA GaRANTía INDEPENDIENTE}

En el intento de identificación de la causa de la garantía independiente, MARTínez CALCERRADA ${ }^{113}$ se refiere a la causa-función de la atribución patrimonial que la garantía produce en el patrimonio del beneficiario, puesto que la garantía independiente no puede desconectarse de la «causa de la relación obligatoria que se establezca» a la que alude el artículo 1263.3 del Código Civil como requisito esencial del contrato. Junto a aquella, la causa de la atribución del contrato de garantía alude a la relación social o comercial cuyo resultado a alcanzar se le garantiza al beneficiario. La causa de la atribución patrimonial de la garantía no puede contradecir su causa-función, consistente en atribuir al beneficiario un aseguramiento absolutamente eficaz de un resultado económico que se espera conseguir de una operación económica determinada, con independencia de las vicisitudes que pudieran afectarle, cumpliendo asimismo dicho aseguramiento la función de constituir un medio de presión para que el obligado cumpla lo que le incumbe.

En tal orden de ideas, se pueden traer aquí a colación las consideraciones de la doctrina francesa ${ }^{114}$ acerca del reequilibrio de intereses producido por la emisión de la garantía independiente, mecanismo de garantía que es exigido por el comprador como condición para la propia celebración del contrato garantizado. En consecuencia, la causa de la garantía independiente parece residir en la producción por el garante de un aseguramiento absoluto a favor de su beneficiario, que se plasma en una alteración del reparto de riesgos comparado con el que se produciría de resultas de la conclusión del contrato subyacente si no se librara la garantía; nuevo reparto de riesgos pactado por las partes de la operación subyacente garantizada, la cual no llegaría a nacer sin el cumplimiento del requisito del otorgamiento de la garantía impuesto por una de las partes del contrato subyacente y aceptado por la otra, finalidad ésta de alcanzar un deseable equilibrio de intereses que lo hace digno de protección por parte del ordenamiento jurídico.

La explicación de la abstracción de la garantía puede requerir alguna precisión adicional. En este sentido, la voluntad de las partes in-

113 Cfr. Martínez Calcerrada, art. cit.,. p. 831.

114 VASSEUR, Rapport de synthése... cit. pp. 319-364. 
tervinientes en la operación de garantía debe ser interpretada en el sentido de que desean que, para asegurar el cobro de la indemnización por el beneficiario, la obligación del banco de pago no se vea interferida ni por las vicisitudes que pudieran afectar al contrato subyacente garantizado, ni por las vicisitudes de la relación de comisión entre ordenante y banco emisor. Ello da contenido a la calificación como abstracta de la promesa unilateral de pago que hace el banco emisor al beneficiario de la garantía. La función misma de garantía desempeñada por el banco garantizando al beneficiario el cobro de la indemnización pactada cuando ésta fuere solicitada, así como el interés del banco en centrar su actuación profesional en la carta de garantía son la base de la consideración de la relación entre banco emisor y beneficiario como promesa abstracta de pago.

A continuación, se debe traer a colación la distinción tradicional entre causa de la obligación y causa del negocio o contrato. La causa de la obligación hace referencia a la cuestión tradicional del cur debetur, o justificación de la existencia de una obligación, mientras que la segunda, o causa del negocio o contrato, hace referencia a la razón por cual se contrajo o celebró el negocio. La causa de la obligación es el hecho constitutivo de la obligación o fuente de la obligación lo que, en el caso de una garantía independiente, está constituido por el negocio jurídico unilateral de emisión de la carta de garantía llevado a cabo por el garante. En cuanto a la causa del negocio o contrato de garantía independiente, y tomando en consideración la exposición de GARRIGUES $^{115}$ y de PAZ ARES ${ }^{116}$ acerca del pactum de cambiando como causa de la letra de cambio, puede apreciarse una similitud entre dicha situación y la que se produce a lo largo de las negociaciones para la conclusión del contrato subyacente, cuando el dueño de la obra, el adquirente de suministros o maquinaria, el deudor general en suma, exige la emisión de una garantía independiente a su favor, de donde surge un pacto específico, entre los demás contenidos en dicho contrato subyacente, que puede ser considerado como la causa del negocio o contrato de garantía independiente.

Tal parece haber sido el punto de vista del TS en las citadas sentencias de 14 de noviembre de 1989 y 8 de mayo de 1991. En la primera de ellas, el TS no apreció la causa de la garantía en el contrato principal o subyacente celebrado entre las partes, sino en el contrato de seguro celebrado entre el deudor (ordenante) y la compañía de seguros

115 Garrigues, Tratado de Derecho mercantil, cit. p. 195.

116 PAZ Ares, Naturaleza jurídica de la letra de cambio, cit., pp. 208-209. 
garante. En la segunda sentencia aludida, el TS no apreció la causa del crédito documentario en el contrato de compraventa, que exigía su pago a través del citado mecanismo ${ }^{117}$, sino que declaró que la causa del crédito documentario radicaba en el contrato de comisión celebrado entre el comprador y el banco.

El recurso a la distinción entre los negocios de base o iniciales, que abren o inician una relación entre partes, frente a los negocios de ejecución que presuponen un negocio antecedente, que juega como su causa, permite concluir que, en el supuesto de una garantía independiente, el negocio de emisión de la carta de garantía es para el banco un negocio de ejecución de la previa relación de mandato mercantil contraída con el ordenante de la garantía. Para el ordenante, es un negocio de ejecución del contrato subyacente garantizado en el que se pactó expresamente el libramiento de la garantía. Es decir, la carta de garantía se sitúa para el banco garante en el plano de la ejecución del contrato de mandato y, para el ordenante, en el plano de la ejecución del contrato subyacente, de forma que el negocio subyacente constituye la causa del negocio de ejecución ${ }^{118}$.

En consecuencia, cabe la afirmación de que la carta de garantía tiene su causa en el contrato de mandato o comisión mercantil celebrado entre el ordenante de la garantía y el banco emisor de la misma que, a su vez, se conecta causalmente con el contrato subyacente garantizado. De acuerdo con ello, la emisión de una garantía a primera demanda es para el banco un negocio de ejecución de la relación de mandato mercantil asumida con quien en el negocio subyacente resulta ser el acreedor general, mandante del banco en la relación de mandato mercantil, y ordenante de la garantía. Igualmente, para quien en el contrato subyacente es acreedor resulta ser un negocio de ejecución de tal contrato subyacente en el que se pactó la entrega de la garantía a favor del deudor general ${ }^{119}$.

D) La abstracción funcional de la garantía independiente y sus efectos

La abstracción funcional de la garantía se manifiesta en aquello que es su nota más característica, como es la voluntad del banco que emite

117 Cfr. Alonso UrebA, art. cit., pp. 465 y ss.

118 Ibidem.

119 Una exposición completamente diferente de la causa de la garantía independiente, en un intento de transposición íntegra de la concepción de la doctrina francesa al respecto en el sistema español, y tratando de establecer causas diferentes de índole más concreta para cada una de las posibles modalidades de garantía en CERDÁ OlmEdo, op. cit., especialmente pp. 148-157. 
la garantía con renuncia al uso de las excepciones que pudieran derivarse del negocio subyacente mediato e inmediato; voluntad del banco de que dicho negocio unilateral (promesa de pago) se desenvuelva con plena independencia respecto de la comisión (antecedente inmediato) y respecto del contrato subyacente (antecedente mediato). Esta voluntad de independencia, que encuentra su apoyo en los artículos 1.255 y 6 (2) CC, se manifiesta en la renuncia a la utilización de las excepciones derivadas del contrato subyacente, consecuencia de la abstracción funcional.

De forma expresa, la STS de 25 de octubre de 1989 atribuye un carácter abstracto a la obligación del asegurador:

«Lubrisur, como beneficiaria...(de) la carta de crédito, tiene un indiscutible derecho a exigirle el pago de la cantidad señalada, siendo la obligación de la Compañía de Crédito y Caución de carácter abstracto en el sentido de ser independiente del contrato inicial entre Stein y Lubrisur. No entenderlo así quebranta la buena fe y lealtad mercantil y los artículos 1.258 del CC y 57 del Cco, pues la póliza...sustituye a la retención para producir su mismo efecto...es luego el contratista-vendedor quien tiene que probar su perfecto cumplimiento para reclamar lo que estime indebidamente retenido...».

En virtud de la consideración indicada, la Compañía de Seguros no puede oponerse al pago aludiendo a la relación entre Stein y Lubrisur, para negar el pago exigido por Lubrisur en virtud de la carta de garantía, pues ésta tiene su causa no en el contrato de obra y suministro entre Stein y Lubrisur, sino en el contrato de seguro entre Stein y Crédito y Caución ${ }^{120}$.

Esta doctrina jurisprudencial se reitera en la STS de 8 de mayo de 1991:

«...el banco...emisor no toma parte directa en la relación sustantiva civil subyacente...sino que actúa como intermediario en una pluralidad negocial, en la que...el vendedor tiene un papel de beneficiario...de una promesa abstracta de pago...».

Vuelve a dispensar la sentencia la calificación de «promesa abstracta de pago» a la declaración dirigida por el banco emisor al vendedor, y se traduce la «abstracción» en la independencia de la relación de crédito documentario respecto de la relación subyacente de compraventa. El crédito documentario tiene su causa en la relación de comisión entre el comprador y el banco. La independencia de la posición del banco frente al vendedor surge de que el banco no opera sobre mercan-

120 Cfr. Alonso Ureba, art. cit., pp. 443 y ss. 
cías, sino sobre documentos, comprometiéndose unilateralmente frente al vendedor a hacerle pago de una cantidad contra entrega de determinados documentos.

La STS de 27 de octubre de 1992 contempló un aval a primer requerimiento y el TS reprodujo la doctrina contenida en la STS de 11 de julio de 1983, así como la doctrina contenida en la STS de 14 de noviembre de 1989 en aplicación de tal doctrina al aval a primer requerimiento, con lo que viene a poner de manifiesto el parelelismo entre ambas figuras así como la abstracción funcional de la garantía independiente.

En cuanto a los efectos de la abstracción de la garantía independiente, en primer lugar, la abstracción implica que el contrato de garantía es totalmente independiente con respecto al contrato subyacente entre ordenante y beneficiario. Ni la nulidad o inexistencia, ni la eficacia, el incumplimiento, la imposibilidad sobrevenida o la pérdida de la cosa objeto del contrato subyacente autorizan a la entidad financiera al incumplimiento de su promesa de pago frente al beneficiario. En segundo lugar, la abstracción se plasma en la independencia entre garantía y contrato de comisión, lo que comporta que el banco queda vinculado frente al beneficiario, aun cuando su relación jurídica con el ordenante adoleciera de cualquier clase de vicio. En tercer lugar, el principio de abstracción también se plasma en la consecuencia, ya mencionada, de que, en caso de divergencias entre las instrucciones recibidas por el banco y el contenido de la garantía, el banco responde frente al beneficiario en los propios términos de esta última. Otro efecto de la independencia radica en que el banco no puede negar el pago al beneficiario, basándose en el hecho de que el ordenante no le haya hecho entrega de la provisión de fondos pactada o haya caído en insolvencia o de cualquier otra forma se precluya el derecho del banco a recuperar el importe adelantado. El garante deberá normalmente proceder al pago de la garantía, pues únicamente cuando sea clara la inexistencia o rescisión del contrato garantizado, o plenamente evidente su cumplimiento, podrá el garante negarse a la realización del pago de la garantía. En consecuencia, el garante únicamente puede oponer al beneficiario las excepciones que deriven de la garantía misma (relativas al consentimiento, objeto, causa y forma); en los demás casos dicho garante debe pagar la garantía cuando se le reclame ${ }^{121}$.

La causa de la garantía determina su grado de autonomía respecto de la operación subyacente (de acuerdo con la función que aquélla

121 Fernández Armesto, Los créditos documentarios irrevocables, Madrid, 1984, pp. 242, y el análisis del citado autor acerca de los efectos de la abstracción funcional del crédito documentario. 
cumple y las exigencias de su causa exterior, o de la atribución), pudiendo concebirse la garantía pura o independiente como cláusula solve et repete, no accesoria, o si se prefiere, como pactum de non petendo, de alcance provisional ${ }^{122}$.

\section{El objeto de la garantía independiente}

El objeto de la garantía independiente es la garantía otorgada al beneficiario mediante el compromiso en ella contenido. El objeto de la obligación del garante es el pago del importe pactado por las partes. Se trate de una u otra de las acepciones del término «objeto», se trate del objeto del contrato o del objeto de la obligación, no parece suscitar dificultades en cuanto a su existencia o a su licitud ${ }^{123}$.

La regulación contractual exige la determinación del objeto del contrato, por lo que será necesario que el importe de la garantía esté determinado o sea determinable. Igualmente, el beneficiario debe hallarse determinado. Dado que las garantías utilizadas son de tipos diferentes, la función de garantía tendrá como consecuencia general la necesaria y precisa mención del contrato subyacente. Ello, sin embargo, no afecta a la independencia de la garantía, que nace en el instante en que se asume el compromiso, aunque permite la más fácil alegación del carácter abusivo de la solicitud de pago o reclamación de la garantía.

El ordenante impone al garante las características de la garantía, y éste último se adapta a las indicaciones proporcionadas por el beneficiario. La doctrina no excluye que el banco pueda incurrir en responsabilidad por faltar a su deber de consejo, especialmente si el ordenante no está habituado a tales compromisos. Asimismo, el garante incurrirá en responsabilidad si transgrediese las instrucciones recibidas emitiendo una garantía a primera demanda cuando el ordenante se ha referido a una fianza o a una garantía condicional o documentaria, o librando una prórroga de la garantía sin el acuerdo del ordenante. Tal responsabilidad podría ser exigida a través de las acciones ejercitables tras el pago.

\section{Javier San Juan Crucelaegui Julio 2002}

122 Martínez CAlCERradA, art. cit., p. 826.

123 Cfr. Simler, Le cautionnement..., p. 718; el autor señala que al consistir la obligación del garante en un pago, éste deberá ser conforme a la reglamentación en materia de control de cambios; en el mismo sentido; SÁnCHEZ-CALERo GuILARTE, El contrato autónomo de garantía... cit., pp. 392-394; HoRn y WyMEERsCH, Bank guarantees, Stand-by letters of credit and performance bonds in International trade, cit. pp. $475 \mathrm{y}$ ss. 